\title{
Consensus Statement on Concussion in Sport-The 4th International Conference on Concussion in Sport Held in Zurich, November 2012
}

\author{
Authors: \\ Paul McCrory, MBBS, PhD, Willem H. Meeuwisse, MD, PhD, Mark Aubry, MD, \\ Robert C. Cantu, MD, Jiří Dvořák, MD, Ruben J. Echemendia, PhD, \\ Lars Engebretsen, MD, PhD, Karen M. Johnston, MD, PhD, Jeffrey S. Kutcher, MD, \\ Martin Raftery, MBBS, Allen Sills, MD, Brian W. Benson, MD, PhD, Gavin A. Davis, MBBS, \\ Richard Ellenbogen, MD, Kevin M. Guskiewicz, PhD, Stanley A. Herring, MD, \\ Grant L. Iverson, PhD, Barry D. Jordan, MD, James Kissick, MD, Michael McCrea, PhD, \\ Andrew S. Mclntosh, PhD, David L. Maddocks, LLB, PhD, Michael Makdissi, MBBS, PhD, \\ Laura Purcell, MD, Margot Putukian, MD, Kathryn Schneider, PhD, \\ Charles H. Tator, MD, PhD, Michael Turner, MD
}

\section{PREAMBLE}

This paper is a revision and update of the recommendations developed following the 1st (Vienna 2001), 2nd (Prague 2004), and 3rd (Zurich 2008) International Consensus Conference on Concussion in Sport, and is based on the deliberations at the 4th International Conference on Concussion in Sport held in Zurich, November 2012 [1-3].

The new 2012 Zurich Consensus statement is designed to build on the principles outlined in the previous documents and to develop further conceptual understanding of this problem by using a formal consensus-based approach. A detailed description of the consensus process is outlined at the end of this document under the "background" section. This document is developed for use by physicians and health care professionals who are involved in the care of injured athletes, whether at the recreational, elite, or professional level.

While agreement exists pertaining to principal messages conveyed within this document, the authors acknowledge that the science of concussion is evolving, and therefore management and return to play (RTP) decisions remain in the realm of clinical judgment on an individualized basis. Readers are encouraged to copy and distribute freely the Zurich Consensus document, the Concussion Recognition Tool (CRT), the Sports Concussion Assessment Tool version 3 (SCAT3), and/or the Child SCAT3 card, and neither is subject to any restriction, provided it is not altered in any way or converted to a digital format. The authors request that the document and/or the accompanying tools be distributed in their full and complete format.

This consensus paper is broken into a number of sections

1. A summary of concussion and its management, with updates from the previous meetings.

2. Background information about the consensus meeting process.

3. A summary of the specific consensus questions discussed at this meeting.

4. The Consensus paper should be read in conjunction with the SCAT3 assessment tool, the Child SCAT3, and the Concussion Recognition Tool (designed for lay use).
This article will also appear in British Journal of Sports Medicine, American Journal of Sports Medicine, Clinical Journal of Sports Medicine, Journal of Athletic Training, Journal of Clincal Neuroscience, Journal of Clinical Sports Medicine (Japanese), Journal of Science and Medicine in Sport, Physician and Sportsmedicine, Neurosurgery, Scandinavian Journal of Science \& Medicine in Sport, South African Sports Medicine Journal, and Canadian Medical Association Journal.

Author affiliations can be found on page 269 


\section{SECTION 1: SPORT CONCUSSION AND ITS MANAGEMENT}

The Zurich 2012 document examines sport concussion and management issues raised in the previous Vienna 2001, Prague 2004, and Zurich 2008 documents, and applies the consensus questions from Section 3 to these areas [1-3].

\section{Definition of Concussion}

Panel discussion regarding the definition of concussion and its separation from mild traumatic brain injury (mTBI) was held. There was acknowledgement by the Concussion in Sport Group (CISG) that, although the terms mTBI and concussion are often used interchangeably in the sporting context and particularly in the U.S. literature, others use the term to refer to different injury constructs. Concussion is the historical term representing low-velocity injuries that cause brain "shaking," resulting in clinical symptoms and that are not necessarily related to a pathologic injury. Concussion is a subset of TBI and the term concussion will be used in this document. It was also noted that the term commotio cerebri is often used in European and other countries. Minor revisions were made to the definition of concussion, and it is defined as follows:

Concussion is a brain injury and is defined as a complex pathophysiological process affecting the brain, induced by biomechanical forces. Several common features that incorporate clinical, pathologic, and biomechanical injury constructs that may be utilized in defining the nature of a concussive head injury include

1. Concussion may be caused either by a direct blow to the head, face, neck, or elsewhere on the body with an "impulsive" force transmitted to the head.

2. Concussion typically results in the rapid onset of short-lived impairment of neurologic function that resolves spontaneously. However, in some cases, symptoms and signs may evolve over a number of minutes to hours.

3. Concussion may result in neuropathologic changes, but the acute clinical symptoms largely reflect a functional disturbance rather than a structural injury, and, as such, no abnormality is seen on standard structural neuroimaging studies.

4. Concussion results in a graded set of clinical symptoms that may or may not involve loss of consciousness. Resolution of the clinical and cognitive symptoms typically follows a sequential course. However, it is important to note that in some cases symptoms may be prolonged.

\section{Recovery of Concussion}

The majority (80\%-90\%) of concussions resolve in a short (7-10 day) period, although the recovery time frame may be longer in children and adolescents. [2] .

\section{Symptoms and Signs of Acute Concussion}

The diagnosis of acute concussion usually involves the assessment of a range of domains, including clinical symptoms, physical signs, cognitive impairment, neurobehavioral features, and sleep disturbance. Furthermore, a detailed concussion history is an important part of the evaluation, both in the injured athlete and when conducting a preparticipation examination. The detailed clinical assessment of concussion is outlined in the SCAT3 and Child SCAT3 forms, which is an Appendix to this document.

The suspected diagnosis of concussion can include one or more of the following clinical domains:

(a) Symptoms-somatic (eg, headache), cognitive (eg, feeling like in a fog), and/or emotional symptoms (eg, lability)

(b) Physical signs (eg, loss of consciousness, amnesia)

(c) Behavioral changes (eg, irritability)

(d) Cognitive impairment (eg, slowed reaction times)

(e) Sleep disturbance (eg, insomnia)

If any one or more of these components is present, a concussion should be suspected and the appropriate management strategy instituted.

\section{On-field or Sideline Evaluation of Acute Concussion}

When a player shows ANY features of a concussion:

(a) The player should be evaluated by a physician or other licensed health care provider onsite by using standard emergency management principles, and particular attention should be given to excluding a cervical spine injury.

(b) The appropriate disposition of the player must be determined by the treating health care provider in a timely manner. If no health care provider is available, the player should be safely removed from practice or play and urgent referral to a physician arranged.

(c) Once the first aid issues are addressed, then an assessment of the concussive injury should be made by using the SCAT3 or other sideline assessment tools.

(d) The player should not be left alone following the injury, and serial monitoring for deterioration is essential over the initial few hours following injury.

(e) A player with diagnosed concussion should not be allowed to return to play on the day of injury. 
Sufficient time for assessment and adequate facilities should be provided for the appropriate medical assessment, both on and off the field, for all injured athletes. In some sports, this may require rule change to allow an appropriate off-field medical assessment to occur without affecting the flow of the game or unduly penalizing the injured player's team. The final determination regarding concussion diagnosis and/or fitness to play is a medical decision based on clinical judgment.

Sideline evaluation of cognitive function is an essential component in the assessment of this injury. Brief neuropsychological test batteries that assess attention and memory function have been shown to be practical and effective. Such tests include the SCAT3, which incorporates the Maddocks questions [4,5], and the Standardized Assessment of Concussion (SAC) [6-8]. It is worth noting that standard orientation questions (eg, time, place, person) have been shown to be unreliable in the sporting situation when compared with memory assessment [5,9]. It is recognized, however, that abbreviated testing paradigms are designed for rapid concussion screening on the sidelines and are not meant to replace comprehensive neuropsychological testing, which should ideally be performed by trained neuropsychologists who are sensitive to subtle deficits that may exist beyond the acute episode; nor should they be used as a stand-alone tool for the ongoing management of sports concussions.

It should also be recognized that the appearance of symptoms or cognitive deficit might be delayed several hours following a concussive episode and that concussion should be seen as an evolving injury in the acute stage.

\section{Evaluation in Emergency Room or Office by Medical Personnel}

An athlete with concussion may be evaluated in the emergency room or doctor's office as a point of first contact following injury or may have been referred from another care provider. In addition to the points outlined above, the key features of this examination should encompass:

(a) A medical assessment including a comprehensive history and detailed neurological examination, including a thorough assessment of mental status, cognitive functioning, gait, and balance.

(b) A determination of the clinical status of the patient, including whether there has been improvement or deterioration since the time of injury. This may involve seeking additional information from parents, coaches, teammates, and eyewitness to the injury.

(c) A determination of the need for emergent neuroimaging in order to exclude a more severe brain injury involving a structural abnormality.

In large part, these points above are included in the SCAT3 assessment.

\section{Concussion Investigations}

A range of additional investigations may be utilized to assist in the diagnosis and/or exclusion of injury. Conventional structural neuroimaging is typically normal in concussive injury. Given that caveat, the following suggestions are made: Brain CT (or where available MR brain scan) contributes little to concussion evaluation but should be employed whenever suspicion of an intracerebral or structural lesion (eg, skull fracture) exists. Examples of such situations may include prolonged disturbance of conscious state, focal neurologic deficit, or worsening symptoms.

Other imaging modalities such as fMRI demonstrate activation patterns that correlate with symptom severity and recovery in concussion [10-14]. While not part of routine assessment at the present time, they nevertheless provide additional insight to pathophysiological mechanisms. Alternative imaging technologies (eg, positron emission tomography, diffusion tensor imaging, magnetic resonance spectroscopy, functional connectivity), while demonstrating some compelling findings, are still at early stages of development and cannot be recommended other than in a research setting.

Published studies, using both sophisticated force plate technology as well as those using less sophisticated clinical balance tests (eg, Balance Error Scoring System [BESS]), have identified acute postural stability deficits lasting approximately 72 hours following sport-related concussion. It appears that postural stability testing provides a useful tool for objectively assessing the motor domain of neurologic functioning and should be considered a reliable and valid addition to the assessment of athletes suffering from concussion, particularly where symptoms or signs indicate a balance component [15-21].

The significance of apolipoprotein (Apo) E4, ApoE promotor gene, tau polymerase, and other genetic markers in the management of sports concussion risk or injury outcome is unclear at this time $[22,23]$. Evidence from human and animal studies in more severe traumatic brain injury demonstrate induction of a variety of genetic and cytokine factors, such as insulin-like growth factor-1 (IGF-1), IGF binding protein-2, fibroblast growth factor, $\mathrm{Cu}-\mathrm{Zn}$ superoxide dismutase, superoxide dismutase-1 (SOD-1), nerve growth factor, glial fibrillary acidic protein (GFAP), and S-100. How such factors are affected in sporting concussion is not known at this stage [24-31]. In addition, biochemical serum and cerebral spinal fluid biomarkers of brain injury (including S-100, neuron specific enolase [NSE], myelin basic protein [MBP], GFAP, tau, etc) have been proposed as means by which cellular damage may be detected if present [32-38]. There is currently insufficient evidence, however, to justify the routine use of these biomarkers clinically.

Different electrophysiological recording techniques (eg, evoked response potential [ERP], cortical magnetic stimulation, and electroencephalography) have demonstrated reproducible abnormalities in the postconcussive state; however, 
not all studies reliably differentiated concussed athletes from controls [39-45]. The clinical significance of these changes remains to be established.

\section{Neuropsychological Assessment}

The application of neuropsychological (NP) testing in concussion has been shown to be of clinical value and contributes significant information in concussion evaluation [4651]. Although in most cases cognitive recovery largely overlaps with the time course of symptom recovery, it has been demonstrated that cognitive recovery may occasionally precede or more commonly follow clinical symptom resolution, suggesting that the assessment of cognitive function should be an important component in the overall assessment of concussion and, in particular, any RTP protocol $[52,53]$. It must be emphasized, however, that NP assessment should not be the sole basis of management decisions. Rather, it should be seen as an aid to the clinical decision-making process in conjunction with a range of assessments of different clinical domains and investigational results.

It is recommended that all athletes should have a clinical neurologic assessment (including assessment of their cognitive function) as part of their overall management. This will normally be done by the treating physician, often in conjunction with computerized NP screening tools.

Formal NP testing is not required for all athletes, however, when this is considered necessary, then it should ideally be performed by a trained neuropsychologist. Although neuropsychologists are in the best position to interpret NP tests by virtue of their background and training, the ultimate return to play decision should remain a medical one in which a multidisciplinary approach, when possible, has been taken. In the absence of NP and other (eg, formal balance assessment) testing, a more conservative RTP approach may be appropriate.

NP testing may be used to assist RTP decisions and is typically performed when an athlete is clinically asymptomatic; however, NP assessment may add important information in the early stages following injury $[54,55]$. There may be particular situations where testing is performed early to assist in determining aspects of management, for example, return to school for a pediatric athlete. This will normally be best determined in consultation with a trained neuropsychologist $[56,57]$.

Baseline NP testing was considered by the panel and was not felt to be required as a mandatory aspect of every assessment, however, may be helpful or add useful information to the overall interpretation of these tests. It also provides an additional educative opportunity for the physician to discuss the significance of this injury with the athlete. At present, there is insufficient evidence to recommend the widespread routine use of baseline NP testing.

\section{Concussion Management}

The cornerstone of concussion management is physical and cognitive rest until the acute symptoms resolve and then a graded program of exertion before medical clearance and RTP. The current published evidence evaluating the effect of rest following a sport-related concussion is sparse. An initial period of rest in the acute symptomatic period following injury (24-48 hours) may be of benefit. Further research to evaluate the long-term outcome of rest, and the optimal amount and type of rest, is needed. In the absence of evidence-based recommendations, a sensible approach involves the gradual return to school and social activities (before contact sports) in a manner that does not result in a significant exacerbation of symptoms.

Low-level exercise for those who are slow to recover may be of benefit, although the optimal timing following injury for initiation of this treatment is currently unknown.

As described above, the majority of injuries will recover spontaneously over several days. In these situations, it is expected that an athlete will proceed progressively through a stepwise RTP strategy [58].

\section{Graduated Return to Play Protocol}

RTP protocol following a concussion follows a stepwise process, as outlined in Table 1.

With this stepwise progression, the athlete should continue to proceed to the next level if asymptomatic at the current level. Generally, each step should take 24 hours so that an athlete would take approximately 1 week to proceed through the full rehabilitation protocol once they are asymptomatic at rest and with provocative exercise. If any postconcussion symptoms occur while in the stepwise program, then the patient should drop back to the previous asymptomatic level and try to progress again after a further 24-hour period of rest has passed.

\section{Same-day RTP}

It was unanimously agreed that no RTP on the day of concussive injury should occur. There are data demonstrating that, at the collegiate and high school level, athletes allowed to RTP on the same day may demonstrate NP deficits postinjury that may not be evident on the sidelines and are more likely to have delayed onset of symptoms [59-65].

\section{The "Difficult" or Persistently Symptomatic Concussion Patient}

Persistent symptoms ( $>10$ days) are generally reported in $10 \%-15 \%$ of concussions. In general, symptoms are not specific to concussion, and it is important to consider other pathologies. Cases of concussion in sport where clinical recovery falls outside the expected window (ie, 10 days) 
Table 1. Graduated return to play protocol

\begin{tabular}{|c|c|c|}
\hline Rehabilitation Stage & $\begin{array}{l}\text { Functional Exercise at Each Stage of } \\
\text { Rehabilitation }\end{array}$ & Objective of Each Stage \\
\hline 1. No activity & Symptom limited physical and cognitive rest. & Recovery \\
\hline 2. Light aerobic exercise & $\begin{array}{l}\text { Walking, swimming, or stationary cycling } \\
\text { keeping intensity }<70 \% \text { maximum permitted } \\
\text { heart rate. No resistance training. }\end{array}$ & Increase heart rate \\
\hline 3. Sport-specific exercise & $\begin{array}{l}\text { Skating drills in ice hockey, running drills in } \\
\text { soccer. No head impact activities. }\end{array}$ & Add movement \\
\hline 4. Non-contact training drills & $\begin{array}{l}\text { Progression to more complex training drills, } \\
\text { eg, passing drills in football and ice hockey. } \\
\text { May start progressive resistance training. }\end{array}$ & $\begin{array}{l}\text { Exercise, coordination, and cognitive } \\
\text { load }\end{array}$ \\
\hline 5. Full contact practice & $\begin{array}{l}\text { Following medical clearance participate in } \\
\text { normal training activities. }\end{array}$ & $\begin{array}{l}\text { Restore confidence and assess } \\
\text { functional skills by coaching staff }\end{array}$ \\
\hline 6. Return to play & Normal game play. & \\
\hline
\end{tabular}

should be managed in a multidisciplinary manner by health care providers with experience in sports-related concussion.

\section{Psychological Management and Mental Health Issues}

Psychological approaches may have potential application in this injury, particularly with the modifiers listed below $[66,67]$. Physicians are also encouraged to evaluate the concussed athlete for affective symptoms, such as depression and anxiety, because these symptoms are common in all forms of traumatic brain injury [58].

\section{The Role of Pharmacologic Therapy}

Pharmacologic therapy in sports concussion may be applied in 2 distinct situations. The first of these situations is the management of specific and/or prolonged symptoms (eg, sleep disturbance, anxiety). The second situation is where drug therapy is used to modify the underlying pathophysiology of the condition with the aim of shortening the duration of the concussion symptoms [68]. In broad terms, this approach to management should be only considered by clinicians experienced in concussion management.

An important consideration in RTP is that concussed athletes should not only be symptom free but also should not be taking any pharmacologic agents or medications that may mask or modify the symptoms of concussion. Where antidepressant therapy may be commenced during the management of a concussion, the decision to return to play while still on such medication must be considered carefully by the treating clinician.

\section{The Role of Preparticipation Concussion Evaluation}

In recognizing the importance of a concussion history and appreciating the fact that many athletes will not recognize all the concussions they may have suffered in the past, a detailed concussion history is of value [69-72]. Such a history may pre-identify athletes who fit into a high-risk category and provides an opportunity for the health care provider to educate the athlete in regard to the significance of concussive injury. A structured concussion history should include specific questions as to previous symptoms of a concussion and length of recovery, not just the perceived number of past concussions. It is also worth noting that dependence upon the recall of concussive injuries by teammates or coaches has been demonstrated to be unreliable [69]. The clinical history should also include information about all previous head, face, or cervical spine injuries because these may also have clinical relevance. It is worth emphasizing that, in the setting of maxillofacial and cervical spine injuries, coexistent concussive injuries may be missed unless specifically assessed. Questions pertaining to disproportionate impact versus symptom severity matching may alert the clinician to a progressively increasing vulnerability to injury. As part of the clinical history, it is advised that details regarding protective equipment employed at time of injury be sought, both for recent and remote injuries.

There is an additional and often unrecognized benefit of the preparticipation physical examination insofar as the evaluation allows for an educative opportunity with the player concerned as well as consideration of modification of playing behavior if required.

\section{Modifying Factors in Concussion Management}

A range of "modifying" factors may influence the investigation and management of concussion and, in some cases, may predict the potential for prolonged or persistent symptoms. However, in some cases, the evidence for their efficacy is limited. These modifiers would be important to consider in a detailed concussion history and are outlined in Table 2.

Female Gender. The role of female gender as a possible modifier in the management of concussion was discussed at 
Table 2. Concussion modifiers

\begin{tabular}{|c|c|}
\hline Factors & Modifier \\
\hline Symptoms & $\begin{array}{l}\text { Number } \\
\text { Duration (> } 10 \text { d) } \\
\text { Severity }\end{array}$ \\
\hline Signs & $\begin{array}{l}\text { Prolonged loss of } \\
\text { consciousness (>1 min), } \\
\text { amnesia }\end{array}$ \\
\hline Sequelae & Concussive convulsions \\
\hline Temporal & $\begin{array}{l}\text { Frequency-repeated } \\
\text { concussions over time } \\
\text { Timing-injuries close } \\
\text { together in time } \\
\text { "Recency" - recent } \\
\text { concussion or TBI }\end{array}$ \\
\hline Threshold & $\begin{array}{l}\text { Repeated concussions } \\
\text { occurring with progressively } \\
\text { less impact force or slower } \\
\text { recovery after each } \\
\text { successive concussion. }\end{array}$ \\
\hline Age & $\begin{array}{l}\text { Child and adolescent ( }<18 \text { y } \\
\text { old) }\end{array}$ \\
\hline Co- and pre-morbidities & $\begin{array}{l}\text { Migraine, depression or other } \\
\text { mental health disorders, } \\
\text { attention deficit } \\
\text { hyperactivity disorder, } \\
\text { learning disabilities, sleep } \\
\text { disorders }\end{array}$ \\
\hline Medication & $\begin{array}{l}\text { Psychoactive drugs, } \\
\text { anticoagulants }\end{array}$ \\
\hline Behavior & Dangerous style of play \\
\hline Sport & $\begin{array}{l}\text { High-risk activity, contact } \\
\text { and collision sport, high } \\
\text { sporting level }\end{array}$ \\
\hline
\end{tabular}

length by the panel. There was not unanimous agreement that the current published research evidence is conclusive enough for this to be included as a modifying factor, although it was accepted that gender may be a risk factor for injury and/or influence injury severity [73-75].

The Significance of Loss of Consciousness (LOC). In the overall management of moderate-to-severe traumatic brain injury, duration of LOC is an acknowledged predictor of outcome [76]. While published findings in concussion describe LOC associated with specific early cognitive deficits, it has not been noted as a measure of injury severity $[77,78]$. Consensus discussion determined that prolonged ( $>1$ minute duration) LOC would be considered as a factor that may modify management.

\section{The Significance of Amnesia and Other Symptoms.}

There is renewed interest in the role of posttraumatic amnesia and its role as a surrogate measure of injury severity $[64,79,80]$. Published evidence suggests that the nature, burden, and duration of the clinical postconcussive symptoms may be more important than the presence or duration of amnesia alone $[77,81,82]$. Further, it must be noted that retrograde amnesia varies with the time of measurement postinjury and hence is poorly reflective of injury severity $[83,84]$.

Motor and Convulsive Phenomena. A variety of immediate motor phenomena (eg, tonic posturing) or convulsive movements may accompany a concussion. Although dramatic, these clinical features are generally benign and require no specific management beyond the standard treatment of the underlying concussive injury $[85,86]$.

Depression. Mental health issues (such as depression) have been reported as a consequence of all levels of traumatic brain injury, including sports-related concussion. Neuroimaging studies with use of fMRI suggest that a depressed mood following concussion may reflect an underlying pathophysiological abnormality consistent with a limbic-frontal model of depression [34,87-97]. While such mental health issues may be multifactorial in nature, it is recommended that the treating physician consider these issues in the management of concussed patients.

\section{Special Populations}

The Child and Adolescent Athlete. The evaluation and management recommendations contained herein can be applied to children and adolescents down to the age of 13 years. Below that age, children report concussion symptoms different from adults and would require age-appropriate symptom checklists as a component of assessment. An additional consideration in assessing the child or adolescent athlete with a concussion is that the clinical evaluation by the health care professional may need to include both patient and parent input, and possibly teacher and school input when appropriate [98-104]. A child SCAT3 has been developed to assess concussion (see Appendix) for subjects aged 5-12 years.

The decision to use NP testing is broadly the same as the adult assessment paradigm, although there are some differences. Timing of testing may differ in order to assist planning in school and home management. If cognitive testing is performed, then it must be developmentally sensitive until late teen years due to the ongoing cognitive maturation that occurs during this period, which, in turn, makes the utility of comparison to either the person's own baseline performance or to population norms limited [20]. In this age group, it is more important to consider the use of trained pediatric neuropsychologists to interpret assessment data, particularly in children with learning disorders and/or ADHD who may need more sophisticated assessment strategies $[56,57,98]$.

It was agreed by the panel that no return to sport or activity should occur before the child/adolescent athlete has managed to return to school successfully. In addition, the concept of "cognitive rest" was highlighted with special reference to a child's need to limit exertion with activities of daily living that may exacerbate symptoms. School atten- 
dance and activities may also need to be modified to avoid provocation of symptoms. Children should not be returned to sport until clinically completely symptom free, which may require a longer time frame than for adults.

Because of the different physiological responses and longer recovery after concussion and specific risks (eg, diffuse cerebral swelling) related to head impact during childhood and adolescence, a more conservative RTP approach is recommended. It is appropriate to extend the amount of time of asymptomatic rest and/or the length of the graded exertion in children and adolescents. It is not appropriate for a child or adolescent athlete with concussion to RTP on the same day as the injury regardless of the level of athletic performance. Concussion modifiers apply even more to this population than adults and may mandate more cautious RTP advice.

\section{Elite Versus Nonelite Athletes}

All athletes, regardless of level of participation, should be managed by using the same treatment and RTP paradigm. The available resources and expertise in concussion evaluation are of more importance in determining management than a separation between elite and nonelite athlete management. Although formal NP testing may be beyond the resources of many sports or individuals, it is recommended that, in all organized high-risk sports, consideration be given to having this cognitive evaluation, regardless of the age or level of performance.

\section{Chronic Traumatic Encephalopathy}

Clinicians need to be mindful of the potential for longterm problems in the management of all athletes. However, it was agreed that CTE represents a distinct tauopathy with an unknown incidence in athletic populations. It was further agreed that a cause and effect relationship has not yet been demonstrated between CTE and concussions or exposure to contact sports [105-114]. At present, the interpretation of causation in the modern CTE case studies should proceed cautiously. It was also recognized that it is important to address the fears of parents and/or athletes from media pressure related to the possibility of CTE.

\section{Injury Prevention}

Protective Equipment: Mouthguards and Helmets. There is no good clinical evidence that currently available protective equipment will prevent concussion, although mouthguards have a definite role in preventing dental and orofacial injury. Biomechanical studies have shown a reduction in impact forces to the brain with the use of head gear and helmets, but these findings have not been translated to show a reduction in concussion incidence. For skiing and snowboarding, there are a number of studies to suggest that helmets provide protection against head and facial injury and hence should be recommended for participants in alpine sports [115-118]. In specific sports, such as cycling and motor and equestrian sports, protective helmets may prevent other forms of head injury (eg, skull fracture) that are related to falling on hard surfaces and may be an important injury prevention issue for those sports [118-130].

Rule Change. Consideration of rule changes to reduce the head injury incidence or severity may be appropriate where a clear-cut mechanism is implicated in a particular sport. An example of this is in football (soccer) where research studies demonstrated that upper limb to head contact in heading contests accounted for approximately 50\% of concussions [131]. As noted earlier, rule changes also may be needed in some sports to allow an effective off-field medical assessment to occur without compromising the athlete's welfare, affecting the flow of the game, or unduly penalizing the player's team. It is important to note that rule enforcement may be a critical aspect of modifying injury risk in these settings and that referees play an important role in this regard.

Risk Compensation. An important consideration in the use of protective equipment is the concept of risk compensation [132]. This is where the use of protective equipment results in behavioral change such as the adoption of more dangerous playing techniques, which can result in a paradoxical increase in injury rates. This may be a particular concern in child and adolescent athletes where head injury rates are often higher than in adult athletes [133-135].

Aggression Versus Violence in Sport. The competitive and/or aggressive nature of sport that makes it fun to play and watch should not be discouraged. However, sporting organizations should be encouraged to address violence that may increase concussion risk $[136,137]$. Fair play and respect should be supported as key elements of sport.

\section{Knowledge Transfer}

Because the ability to treat or reduce the effects of concussive injury after the event is minimal, education of athletes, colleagues, and the general public is a mainstay of progress in this field. Athletes, referees, administrators, parents, coaches, and health care providers must be educated regarding the detection of concussion, its clinical features, assessment techniques, and principles of safe RTP. Methods to improve education, including Web-based resources, educational videos, and international outreach programs, are important in delivering the message. In addition, concussion working groups, plus the support and endorsement of enlightened sport groups such as Fédération Internationale de Football Association (FIFA), International Olympic Commission (IOC), International Rugby Board (IRB), and International 
Ice Hockey Federation (IIHF) who initiated this endeavor have enormous value and must be pursued vigorously. Fair play and respect for opponents are ethical values that should be encouraged in all sports and sporting associations. Similarly, coaches, parents, and managers play an important part in ensuring these values are implemented on the field of play [58,138-150].

\section{SECTION 2: STATEMENT ON BACKGROUND TO THE CONSENSUS PROCESS}

In November 2001, the 1st International Conference on Concussion in Sport was held in Vienna, Austria. This meeting was organized by the IIHF in partnership with FIFA and the Medical Commission of the IOC. As part of the resulting mandate for the future, the need for leadership and future updates were identified. The 2nd International Conference on Concussion in Sport was organized by the same group, with the additional involvement of the IRB and was held in Prague, Czech Republic, in November 2004. The original aims of the symposia were to provide recommendations for the improvement of safety and health of athletes who suffer concussive injuries in ice hockey, rugby, football (soccer) as well as other sports. To this end, a range of experts were invited to both meetings to address specific issues of epidemiology, basic and clinical science, injury grading systems, cognitive assessment, new research methods, protective equipment, management, prevention, and long-term outcome $[1,2]$.

The 3rd International Conference on Concussion in Sport was held in Zurich, Switzerland, on October 29-30, 2008, and was designed as a formal consensus meeting following the organizational guidelines set forth by the U.S. National Institutes of Health. (Details of the consensus methodology can be obtained at http://consensus.nih.gov/ABOUTCDP. $\mathrm{htm}$.) The basic principles governing the conduct of a consensus development conference are summarized below:

1. A broad-based nongovernment, nonadvocacy panel was assembled to give balanced, objective, and knowledgeable attention to the topic. Panel members excluded anyone with scientific or commercial conflicts of interest and included researchers in clinical medicine, sports medicine, neuroscience, neuroimaging, athletic training, and sports science.

2. These experts presented data in a public session, followed by inquiry and discussion. The panel then met in an executive session to prepare the consensus statement.

3. A number of specific questions were prepared and posed in advance to define the scope and guide the direction of the conference. The principal task of the panel was to elucidate responses to these questions. These questions are outlined below.
4. A systematic literature review was prepared and circulated in advance for use by the panel in addressing the conference questions.

5. The consensus statement is intended to serve as the scientific record of the conference.

6. The consensus statement will be widely disseminated to achieve maximum impact on both current health care practice and future medical research.

The panel chairperson (W.M.) did not identify with any advocacy position. The chairperson was responsible for directing the consensus session and guiding the panel's deliberations. Panelists were drawn from clinical practice, academics, and research in the field of sports-related concussion. They do not represent organizations per se but were selected for their expertise, experience, and understanding of this field.

The 4th International Conference on Concussion in Sport was held in Zurich, Switzerland, on November 1-3, 2012, and followed the same outline as for the 3rd meeting. All speakers, consensus panel members, and abstract authors were required to sign an ICMJE Form for Disclosure of Potential Conflicts of Interest. Detailed information related to each author's affiliations and conflicts of interests are at the end of this article.

\section{Medical-Legal Considerations}

This consensus document reflects the current state of knowledge and will need to be modified according to the development of new knowledge. It provides an overview of issues that may be of importance to health care providers involved in the management of sports-related concussion. It is not intended as a standard of care and should not be interpreted as such. This document is only a guide and is of a general nature, consistent with the reasonable practice of a health care professional. Individual treatment will depend on the facts and circumstances specific to each individual case. It is intended that this document will be formally reviewed and updated before December 1, 2016.

\section{SECTION 3: ZURICH 2012 CONSENSUS QUESTIONS}

Note that each question is the subject of a separate systematic review that is published in the British Journal of Sports Medicine (2013;47:5). As such, all citations and details of each topic will be covered in those reviews.

1. When you assess an athlete acutely and they do not have concussion, what is it? Is a cognitive injury the key component of concussion in making a diagnosis?

The consensus panel agreed that concussion is an evolving injury in the acute phase with rapidly changing clinical signs 
and symptoms, which may reflect the underlying physiological injury in the brain. Concussion is considered to be among the most complex injuries in sports medicine to diagnose, assess, and manage. The majority of concussions in sport occur without loss of consciousness or frank neurologic signs. At present, there is no perfect diagnostic test or marker that clinicians can rely on for an immediate diagnosis of concussion in the sporting environment. Because of this evolving process, it is not possible to rule out concussion when an injury event occurs associated with a transient neurological symptom. All such cases should be removed from the playing field and assessed for concussion by the treating physician or health care provider as discussed below. It was recognized that a cognitive deficit is not necessary for acute diagnosis as it either may not be present or detected on examination.

2. Are the existing tools/examinations sensitive and reliable enough on the day of injury to make or exclude a diagnosis of concussion?

Concussion is a clinical diagnosis based largely on the observed injury mechanism, signs, and symptoms. The vast majority of sport-related concussions (hereafter, referred to as concussion) occur without loss of consciousness or frank neurologic signs [151-154]. In milder forms of concussion, the athlete might be slightly confused, without clearly identifiable amnesia. In addition, most concussions cannot be identified or diagnosed by neuroimaging techniques (eg, computed tomography or magnetic resonance imaging). Several well-validated neuropsychological tests are appropriate for use in the assessment of acute concussion in the competitive sporting environment. These tests provide important data on symptoms and functional impairments that clinicians can incorporate into their diagnostic formulation but should not solely be used to diagnose concussion.

3. What is the best practice for evaluating an adult athlete with concussion on the "field of play" in 2012?

Recognizing and evaluating concussion in the adult athlete on the field is a challenging responsibility for the health care provider. Performing this task is often a rapid assessment in the midst of competition with a time constraint and the athlete eager to play. A standardized objective assessment of injury, which includes excluding more serious injury, is critical in determining disposition decisions for the athlete. The on-field evaluation of sportrelated concussion is often a challenge given the elusiveness and variability of presentation, difficulty in making a timely diagnosis, specificity and sensitivity of sideline assessment tools, and the reliance on symptoms. Despite these challenges, the sideline evaluation is based on recognition of injury, assessment of symptoms, cognitive and cranial nerve function, and balance. Serial assessments are often necessary. Concussion is often an evolving injury, and signs and symptoms may be delayed. Therefore, erring on the side of caution (keeping an athlete out of participation when there is any suspicion for injury) is important. A standardized assessment of concussion is useful in the assessment of the athlete with suspected concussion but should not take the place of clinician judgment.

\section{How can the SCAT2 be improved?}

It was agreed that a variety of measures should be employed as part of the assessment of concussion to provide a more complete clinical profile for the concussed athlete. Important clinical information can be ascertained in a streamlined manner through the use of a multimodal instrument such as the Sport Concussion Assessment Tool (SCAT). A baseline assessment is advised wherever possible. However, it is acknowledged that further validity studies need to be performed to answer this specific issue.

A future SCAT test battery (ie, SCAT3) should include an initial assessment of injury severity using the Glasgow Coma Scale (GCS), immediately followed by observing and documenting concussion signs. Once this is complete, symptom endorsement and symptom severity, neurocognitive function, and balance function should be assessed in any athlete suspected of sustaining a concussion. It is recommended that these latter steps be conducted following a minimum 15-minute rest period on the sideline to avoid the influence of exertion or fatigue on the athlete's performance. While it is noted that this time frame is an arbitrary one, nevertheless, the expert panel agreed that a period of rest was important prior to assessment. Future research should consider the efficacy for inclusion of vision tests such as the King Devick Test and clinical reaction time tests $[155,156]$. Recent studies suggest that these may be useful additions to the sideline assessment of concussion. However, the need for additional equipment may make them impractical for sideline use. It was further agreed that the SCAT3 would be suitable for adults and youths age 13 years old and over, while a new tool (Child SCAT3) has been developed for younger children.

5. Advances in neuropsychology: Are computerized tests sufficient for concussion diagnosis?

Sport-related concussions are frequently associated with one or more symptoms, impaired balance, and/or cognitive deficits. These problems can be measured by using symptom scales, balance testing, and neurocognitive testing. All 3 modalities can identify significant changes in the first few days following injury, generally with normalization over 1-3 weeks. The presentation of symptoms and the rate of recovery can be variable, which reinforces the value of assessing all 3 areas as part of a comprehensive sport concussion program.

Neuropsychological assessment has been described by the Concussion in Sport Group as a "cornerstone" of concussion management. Neuropsychologists are uniqu- 
ely qualified to interpret neuropsychological tests and can play an important role within the context of a multifaceted-multimodal and multidisciplinary approach to managing sport-related concussion. Concussion management programs that use neuropsychological assessment to assist in clinical decision making have been instituted in professional sports, colleges, and high schools. Brief computerized cognitive evaluation tools are the mainstay of these assessments worldwide given the logistical limitation in accessing trained neuropsychologists; however, it should be noted that these are not substitutes for formal neuropsychological assessment. At present, there is insufficient evidence to recommend the widespread routine use of baseline neuropsychological testing.

7. What evidence exists for new strategies and/or technologies in the diagnosis of concussion and assessment of recovery?

A number of novel technological platforms exist to assess concussion, including (but not limited to) iPhone/ smart phone apps, quantitative electroencephalography, robotics-sensory motor assessment, telemedicine, eyetracking technology, functional imaging and/or advanced neuroimaging, and head impact sensors. At this stage, only limited evidence exists for their role in this setting, and none have been validated as diagnostic. It will be important to reconsider the role of these technologies once evidence is developed.

8. Advances in the management of sport concussion: What is evidence for concussion therapies?

The current evidence evaluating the effect of rest and treatment following a sport-related concussion is sparse. An initial period of rest may be of benefit. However, further research to evaluate the long-term outcome of rest, and the optimal amount and type of rest, is needed. Low-level exercise for those who are slow to recover may be of benefit, although the optimal timing following injury for initiation of this treatment is currently unknown. Multimodal physiotherapy treatment for individuals with clinical evidence of cervical spine and/or vestibular dysfunction may be of benefit. There is a strong need for high-level studies evaluating the effects of a resting period, pharmacologic interventions, rehabilitative techniques, and exercise for individuals who have sustained a sportrelated concussion.

9. The difficult concussion patient: What is the best approach to investigation and management of persistent ( $>10$ days) postconcussive symptoms?

Persistent symptoms ( $>10$ days) are generally reported in 10\%-15\% of concussions. This may be higher in certain sports (eg, elite ice hockey) and populations (eg, children). In general, symptoms are not specific to concussion, and it is important to consider and manage coexistent pathologies. Investigations may include formal neuropsychological testing and conventional neuroimag- ing to exclude structural pathology. Currently, there is insufficient evidence to recommend routine clinical use of advanced neuroimaging techniques or other investigative strategies. Cases of concussion in sport where clinical recovery falls outside the expected window (ie, 10 days) should be managed in a multidisciplinary manner by health care providers with experience in sports-related concussion. Important components of management after the initial period of physical and cognitive rest include associated therapies, such as cognitive, vestibular, physical, and psychological therapy; consideration of assessment of other causes of prolonged symptoms; and consideration of commencement of a graded exercise program at a level that does not exacerbate symptoms.

10. Revisiting concussion modifiers: How should the evaluation and management of acute concussion differ in specific groups?

The literature demonstrates that number and severity of symptoms and previous concussions are associated with prolonged recovery and/or increased risk of complications. Brief loss of consciousness (LOC), duration of posttraumatic amnesia, and/or impact seizures do not reliably predict outcome following concussion, although a cautious approach should be taken in an athlete with prolonged LOC (ie, >1 minute). Children generally take longer to recover from concussions, and assessment batteries have yet to be validated in the younger age group. Currently, there are insufficient data on the influence of genetics and gender on outcome following concussion. Several modifiers are associated with prolonged recovery or increased risk of complications following concussion and have important implications for management. Children with concussion should be managed conservatively, with the emphasis on return to learn before return to sport. In cases of concussion managed with limited resources (eg, nonelite players), a conservative approach should also be taken such that the athlete does not return to sport until fully recovered

11. What are the most effective risk-reduction strategies in sport concussion? From protective equipment to policy?

No new valid evidence was provided to suggest that the use of current standard headgear in rugby or mouthguards in American football can significantly reduce players' risk of concussion. No evidence was provided to suggest an association between neck strength increases and concussion risk reduction. There was evidence to suggest that eliminating body checking from Pee Wee ice hockey (ages 11-12 years), and fair-play rules in ice hockey were effective injury prevention strategies. Helmets need to be able to protect from impacts resulting in a head change in velocity of up to $10 \mathrm{~m} / \mathrm{s}$ in professional American football, and up to $7 \mathrm{~m} / \mathrm{s}$ in professional Australian football. It also appears that helmets must be capable of reducing head resultant linear acceleration to 
below $50 \mathrm{~g}$ and angular acceleration components to below $1500 \mathrm{rad} / \mathrm{s}^{2}$ to optimize their effectiveness. Given that a multifactorial approach is needed for concussion prevention, well-designed and sport-specific prospective analytical studies of sufficient power are warranted for mouthguards, headgear and helmets, facial protection, and neck strength. Measuring the effect of rule changes should also be addressed with future studies, not only assessing new rule changes or legislation but also alteration or reinforcement to existing rules.

12. What is the evidence for chronic concussionrelated changes? Behavioral, pathologic, and clinical outcomes.

It was agreed that CTE represents a distinct tauopathy with an unknown incidence in athletic populations. It was further agreed that CTE was not related to concussions alone or simply exposure to contact sports. At present, there are no published epidemiologic, cohort, or prospective studies relating to modern CTE. Due to the nature of the case reports and pathologic case series that have been published, it is not possible to determine the causality or risk factors with any certainty. As such, the speculation that repeated concussion or subconcussive impacts cause CTE remains unproven. The extent to which age-related changes, psychiatric or mental health illness, alcohol or drug use, or coexisting medical or dementing illnesses contribute to this process is largely unaccounted for in the published literature. At present, the interpretation of causation in the modern CTE case studies should proceed cautiously. It was also recognized that it is important to address the fears of parents and/or athletes from media pressure related to the possibility of CTE.

13. From consensus to action: How do we optimize knowledge transfer, education, and ability to influence policy?

The value of knowledge transfer (KT) as part of concussion education is increasingly becoming recognized. Target audiences benefit from specific learning strategies. Concussion tools exist, but their effectiveness and impact require further evaluation. The media are valuable in drawing attention to concussion, but efforts need to ensure that the public is aware of the right information. Social media as a concussion education tool are becoming more prominent. Implementation of KT models is one approach that organizations can use to assess knowledge gaps; identify, develop, and evaluate education strategies; and use the outcomes to facilitate decision making. Implementing KT strategies requires a defined plan. Identifying the needs, learning styles, and preferred learning strategies of target audiences, coupled with evaluation, should be a piece of the overall concussion education puzzle to have an impact on enhancing knowledge and awareness.

\section{REFERENCES}

1. Aubry M, Cantu R, Dvorak J, et al. Summary and agreement statement of the 1st International Symposium on Concussion in Sport, Vienna 2001. Clin J Sport Med 2002;12:6-11.

2. McCrory $P$, Johnston $K$, Meeuwisse $W$, et al. Summary and agreement statement of the 2nd International Conference on Concussion in Sport, Prague 2004. Br J Sports Med 2005;39:196-204.

3. McCrory P, Meeuwisse W, Johnston K, et al. Consensus Statement on Concussion in Sport: The Third International Conference on Concussion in Sport held in Zurich, November 2008. Phys Sportsmed 2009; 37:141-159

4. Maddocks D, Dicker G. An objective measure of recovery from concussion in Australian rules footballers. Sport Health 1989; 7(Suppl):6-7.

5. Maddocks DL, Dicker GD, Saling MM. The assessment of orientation following concussion in athletes. Clin J Sport Med 1995;5:32-35.

6. McCrea M. Standardized mental status assessment of sports concussion. Clin J Sport Med 2001;11:176-181.

7. McCrea M, Kelly J, Randolph C, et al. Standardised assessment of concussion (SAC): On site mental status evaluation of the athlete. J Head Trauma Rehab. 1998;13:27-36.

8. McCrea M, Randolph C, Kelly J. The Standardized Assessment of Concussion (SAC): Manual for Administration, Scoring and Interpretation. 2nd ed. Waukesha, WI: 2000, 22-45

9. McCrea M, Kelly JP, Kluge J, Ackley B, Randolph C. Standardized assessment of concussion in football players. Neurology 1997;48:586588.

10. Chen J, Johnston K, Collie A, McCrory P, Ptito A. A validation of the post concussion symptom scale in the assessment of complex concussion using cognitive testing and functional MRI. J Neurol Neurosurg Psychiatry 2007;78:1231-1238.

11. Chen J, Johnston K, Frey S, Petrides M, Worsley K, Ptito A. Functional abnormalities in symptomatic concussed athletes: An fMRI study. Neuroimage 2004;22:68-82.

12. Chen JK, Johnston KM, Collie A, McCrory P, Ptito A. (14) Association between symptom severity, cogsport tests results, and functional MRI activation in symptomatic concussed athletes. Clin J Sport Med 2004; 14:379.

13. Chen JK, Johnston KM, Collie A, McCrory P, Ptito A. behavioural and functional imaging outcomes in symptomatic concussed athletes measured with cogsport and functional MRI. Br J Sport Med 2004;38:659.

14. Ptito A, Chen JK, Johnston KM. Contributions of functional magnetic resonance imaging (fMRI) to sport concussion evaluation. NeuroRehabilitation 2007;22:217-227.

15. Guskiewicz K. Postural stability assessment following concussion. Clin J Sport Med 2001;11:182-190.

16. Guskiewicz KM. Assessment of postural stability following sportrelated concussion. Curr Sports Med Rep 2003;2:24-30.

17. Guskiewicz KM, Ross SE, Marshall SW. Postural stability and neuropsychological deficits after concussion in collegiate athletes. J Athl Train 2001;36:263-273.

18. Cavanaugh JT, Guskiewicz KM, Giuliani C, Marshall S, Mercer V, Stergiou N. Detecting altered postural control after cerebral concussion in athletes with normal postural stability. Br J Sports Med 2005;39:805-811.

19. Cavanaugh JT, Guskiewicz KM, Giuliani C, Marshall S, Mercer VS, Stergiou N. Recovery of postural control after cerebral concussion: New insights using approximate entropy. J Athl Train 2006;41:305313.

20. Cavanaugh JT, Guskiewicz KM, Stergiou N. A nonlinear dynamic approach for evaluating postural control: New directions for the management of sport-related cerebral concussion. Sports Med 2005; 35:935-950. 
21. Fox ZG, Mihalik JP, Blackburn JT, Battaglini CL, Guskiewicz KM. Return of postural control to baseline after anaerobic and aerobic exercise protocols. J Athl Train 2008;43:456-463.

22. Kristman VL, Tator $\mathrm{CH}$, Kreiger $\mathrm{N}$, et al. Does the apolipoprotein epsilon 4 allele predispose varsity athletes to concussion? A prospective cohort study. Clin J Sport Med 2008;18:322-328.

23. Terrell TR, Bostick RM, Abramson R, et al. APOE, APOE promoter, and Tau genotypes and risk for concussion in college athletes. Clin J Sport Med 2008;18:10-17.

24. Vagnozzi R, Tavazzi B, Signoretti $S$, et al. Temporal window of metabolic brain vulnerability to concussions: Mitochondrial-related impairment-Part I. Neurosurgery 2007;61:379-388; discussion 88-89.

25. Hang $\mathrm{CH}$, Chen $\mathrm{G}$, Shi JX, Zhang $\mathrm{X}$, Li JS. Cortical expression of nuclear factor kappaB after human brain contusion. Brain Res 2006; 1109:14-21.

26. Peng RY, Gao YB, Xiao XY, et al. Study on the expressions of basic fibroblast growth factor and nervous growth factor genes in rat cerebral concussion [in Chinese, with English abstract]. Zhongguo Wei Zhong Bing Ji Jiu Yi Xue 2003;15:213-216

27. Yunoki M, Kawauchi M, Ukita N, et al. Effects of lecithinized SOD on sequential change in SOD activity after cerebral contusion in rats. Acta Neurochir Suppl 1998;71:142-145.

28. Hinkle DA, Baldwin SA, Scheff SW, Wise PM. GFAP and S100beta expression in the cortex and hippocampus in response to mild cortical contusion. J Neurotrauma 1997;14:729-738.

29. Holmin S, Schalling M, Hojeberg B, Nordqvist AC, Skeftruna AK, Mathiesen T. Delayed cytokine expression in rat brain following experimental contusion. J Neurosurg 1997;86:493-504.

30. Sandberg Nordqvist AC, von Holst H, Holmin S, Sara VR, Bellander $\mathrm{BM}$, Schalling M. Increase of insulin-like growth factor (IGF)-1, IGF binding protein-2 and - 4 mRNAs following cerebral contusion. Brain Res Mol Brain Res 1996;38:285-293.

31. Fukuhara $T$, Nishio $S$, Ono $Y$, Kawauchi M, Asari $S$, Ohmoto $T$. Induction of $\mathrm{Cu}, \mathrm{Zn}$-superoxide dismutase after cortical contusion injury during hypothermia. Brain Res 1994;657:333-336.

32. Begaz $T$, Kyriacou DN, Segal J, Bazarian JJ. Serum biochemical markers for post-concussion syndrome in patients with mild traumatic brain injury. J Neurotrauma 2006;23:1201-1210.

33. de Boussard CN, Lundin A, Karlstedt D, Edman G, Bartfai A, Borg J. S100 and cognitive impairment after mild traumatic brain injury. J Rehabil Med 2005;37:53-57.

34. Lima DP, Simao Filho C, Abib Sde C, de Figueiredo LF. Quality of life and neuropsychological changes in mild head trauma. Late analysis and correlation with S100B protein and cranial CT scan performed at hospital admission. Injury 2008;39:604-611.

35. Ma M, Lindsell CJ, Rosenberry CM, Shaw GJ, Zemlan FP. Serum cleaved tau does not predict postconcussion syndrome after mild traumatic brain injury. Am J Emerg Med 2008;26:763-768.

36. Stalnacke BM, Tegner $Y$, Sojka P. Playing ice hockey and basketball increases serum levels of S-100B in elite players: A pilot study. Clin J Sport Med 2003;13:292-302.

37. Stalnacke BM, Tegner Y, Sojka P. Playing soccer increases serum concentrations of the biochemical markers of brain damage S-100B and neuron-specific enolase in elite players: A pilot study. Brain Inj 2004; 18:899-909

38. Townend $\mathrm{W}$, Ingebrigtsen $\mathrm{T}$. Head injury outcome prediction: A role for protein S-100B? Injury 2006;37:1098-1108.

39. Boutin D, Lassonde M, Robert M, Vanassing P, Ellemberg D. Neurophysiological assessment prior to and following sports-related concussion during childhood: A case study. Neurocase 2008;14:239248.

40. De Beaumont L, Brisson B, Lassonde M, Jolicoeur P. Long-term electrophysiological changes in athletes with a history of multiple concussions. Brain Inj 2007;21:631-644.
41. De Beaumont L, Lassonde M, Leclerc S, Theoret H. Long-term and cumulative effects of sports concussion on motor cortex inhibition. Neurosurgery 2007;61:329-336; discussion 36-37.

42. Gaetz $M$, Weinberg $H$. Electrophysiological indices of persistent postconcussion symptoms. Brain Inj 2000;14:815-832

43. Gosselin $N$, Theriault $M$, Leclerc S, Montplaisir J, Lassonde M. Neurophysiological anomalies in symptomatic and asymptomatic concussed athletes. Neurosurgery 2006;58:1151-1161; discussion 1161.

44. Lavoie ME, Dupuis F, Johnston KM, Leclerc S, Lassonde M. Visual p300 effects beyond symptoms in concussed college athletes. J Clin Exp Neuropsychol 2004;26:55-73

45. Rousseff RT, Tzvetanov P, Atanassova PA, Volkov I, Hristova I. Correlation between cognitive $\mathrm{P} 300$ changes and the grade of closed head injury. Electromyogr Clin Neurophysiol 2006;46:275-277.

46. Collie A, Darby D, Maruff P. Computerised cognitive assessment of athletes with sports related head injury. Br J Sports Med 2001;35:297302.

47. Collie A, Maruff P. Computerised neuropsychological testing. Br J Sports Med 2003;37:2-3

48. Collie A, Maruff P, McStephen M, Darby DG. Psychometric issues associated with computerised neuropsychological assessment of concussed athletes. Br J Sports Med 2003;37:556-559.

49. Collins MW, Grindel SH, Lovell MR, et al. Relationship between concussion and neuropsychological performance in college football players [see comments]. JAMA 1999;282:964-970

50. Lovell MR. The relevance of neuropsychologic testing for sportsrelated head injuries. Curr Sports Med Rep 2002;1:7-11.

51. Lovell MR, Collins MW. Neuropsychological assessment of the college football player. J Head Trauma Rehabil 1998;13:9-26

52. Bleiberg J, Cernich AN, Cameron K, et al. Duration of cognitive impairment after sports concussion. Neurosurgery 2004;54:10731078; discussion 8-80.

53. Bleiberg J, Warden D. Duration of cognitive impairment after sports concussion. Neurosurgery 2005;56:E1166.

54. Broglio SP, Macciocchi SN, Ferrara MS. Neurocognitive performance of concussed athletes when symptom free. J Athl Train 2007;42:504508.

55. Broglio SP, Macciocchi SN, Ferrara MS. Sensitivity of the concussion assessment battery. Neurosurgery 2007;60:1050-1057; discussion 7-8.

56. Gioia G, Janusz J, Gilstein K, Iverson GL. Neuropsychological management of consussion in children and adolescents: Effects of age and gender on ImPact. [abstract]. Br J Sp Med 2004;38:657.

57. McCrory P, Collie A, Anderson V, Davis G. Can we manage sport related concussion in children the same as in adults? Br J Sports Med 2004:38:516-519.

58. Johnston K, Bloom G, Ramsay J, et al. Current Concepts in Concussion Rehabilitation. Curr Sports Med Rep 2004;3:316-323.

59. Guskiewicz KM, McCrea M, Marshall SW, et al. Cumulative effects associated with recurrent concussion in collegiate football players. JAMA 2003;290:2549-2555.

60. Lovell M, Collins M, Bradley J. Return to play following sports-related concussion. Clin Sports Med 2004;23:421-441, ix.

61. Collins M, Field M, Lovell M, GI, et al. Relationship between postconcussion headache and neuropsychological test performance in high school athletes. Am J Sports Med 2003;31:168-173

62. Collins M, Grindel S, Lovell M, et al. Relationship between concussion and neuropsychological performance in college football players. JAMA 1999;282:964-970.

63. Collins MW, Lovell MR, Iverson GL, Cantu RC, Maroon JC, Field M Cumulative effects of concussion in high school athletes. Neurosurgery 2002;51:1175-1179; discussion 80-1. 
64. McCrea M, Guskiewicz KM, Marshall SW, et al. Acute effects and recovery time following concussion in collegiate football players. JAMA 2003;290:2556-2563.

65. McCrea M, Hammeke T, Olsen G, Leo P, Guskiewicz K. Unreported concussion in high school football players: Implications for prevention. Clin J Sport Med 2004;14:13-17.

66. Bloom G, Horton A, McCrory P, Johnston K. Sport psychology and concussion: New impacts to explore. Br J Sports Med 2004;38:519521.

67. Weiss MR, Gill DL. What goes around comes around: Re-emerging themes in sport and exercise psychology. Res Q Exerc Sport 2005; 76(Suppl):S71-S87.

68. McCrory P. Should we treat concussion pharmacologically? The need for evidence based pharmacological treatment for the concussed athlete. Br J Sports Med 2002;36:3-5.

69. McCrory P. Preparticipation assessment for head injury. Clin J Sport Med 2004;14:139-144.

70. Johnston KM, Lassonde M, Ptito A. A contemporary neurosurgical approach to sport-related head injury: The McGill Concussion Protocol. J Am Coll Surg 2001;192:515-524.

71. Delaney J, Lacroix V, Leclerc S, Johnston K. Concussions during the 1997 Canadian Football League Season. Clin J Sport Med 2000;10:9-14

72. Delaney J, Lacroix V, Leclerc S, Johnston K. Concussions among university football and soccer players. Clin J Sport Med 2002;12:331338.

73. Gessel LM, Fields SK, Collins CL, Dick RW, Comstock RD. Concussions among United States high school and collegiate athletes. J Athl Train 2007;42:495-503.

74. Dvorak J, Junge A, Fuller C, McCrory P. Medical issues in women's football. Br J Sports Med 2007;41(Suppl 1):il.

75. Dvorak J, McCrory P, Kirkendall DT. Head injuries in the female football player: Incidence, mechanisms, risk factors and management. Br J Sports Med 2007;41 (Suppl 1): i44-i46.

76. Jennett $B$, Bond M. Assessment of outcome after severe brain damage: A practical scale. Lancet 1975;1:480-484.

77. Leninger B, Gramling S, Farrell A, Kreutzer J, Peck E. Neuropsychological deficits in symptomatic minor head injury patients after concussion and mild concussion. J Neurol Neurosurg Psychiatry 1990; 53:293-296.

78. Lovell M, Iverson G, Collins M, McKeag D, Maroon J. Does loss of consciousness predict neuropsychological decrements after concussion. Clin J Sport Med 1999;9:193-199.

79. McCrea M, Kelly J, Randolph $C$, Cisler R, Berger L. Immediate neurocognitive effects of concussion. Neurosurgery 2002;50:10321042 .

80. Cantu RC. Posttraumatic retrograde and anterograde amnesia: Pathophysiology and implications in grading and safe return to play. J Athl Train 2001;36:244-248

81. Lovell MR, Collins MW, Iverson GL, et al. Recovery from mild concussion in high school atheltes. J Neurosurg 2003;98:296-301.

82. McCrory PR, Ariens $T$, Berkovic SF. The nature and duration of acute concussive symptoms in Australian football. Clin J Sport Med 2000; 10:235-238.

83. Yarnell $P$, Lynch $S$. The 'ding': amnestic state in football trauma. Neurology 1973;23:196-197.

84. Yarnell PR, Lynch S. Retrograde memory immediately after concussion. Lancet 1970;I:863-864.

85. McCrory PR, Berkovic SF. Video analysis of acute motor and convulsive manifestations in sport-related concussion. Neurology 2000;54: 1488-1491.

86. McCrory PR, Bladin PF, Berkovic SF. Retrospective study of concussive convulsions in elite Australian rules and rugby league footballers: Phenomenology, aetiology, and outcome. BMJ 1997; 314:171-174.
87. Fleminger $S$. Long-term psychiatric disorders after traumatic brain injury. Eur J Anaesthesiol Suppl 2008;42:123-130.

88. Chen JK, Johnston KM, Petrides M, Ptito A. Neural substrates of symptoms of depression following concussion in male athletes with persisting postconcussion symptoms. Arch Gen Psychiatry 2008;65: 81-89

89. Bryant RA. Disentangling mild traumatic brain injury and stress reactions. N Engl J Med 2008;358:525-527.

90. Vanderploeg RD, Curtiss G, Luis CA, Salazar AM. Long-term morbidities following self-reported mild traumatic brain injury. J Clin Exp Neuropsychol 2007;29:585-598

91. Guskiewicz KM, Marshall SW, Bailes J, et al. Recurrent concussion and risk of depression in retired professional football players. Med Sci Sports Exerc 2007;39:903-909.

92. Kashluba S, Casey JE, Paniak C. Evaluating the utility of ICD-10 diagnostic criteria for postconcussion syndrome following mild traumatic brain injury. J Int Neuropsychol Soc 2006;12:111-118.

93. Iverson GL. Misdiagnosis of the persistent postconcussion syndrome in patients with depression. Arch Clin Neuropsychol 2006;21:303310 .

94. Chamelian L, Feinstein A. The effect of major depression on subjective and objective cognitive deficits in mild to moderate traumatic brain injury. J Neuropsychiatry Clin Neurosci 2006;18:33-38.

95. Mooney G, Speed J, Sheppard S. Factors related to recovery after mild traumatic brain injury. Brain Inj 2005;19:975-987.

96. Broshek DK, Freeman JR. Psychiatric and neuropsychological issues in sport medicine. Clin Sports Med 2005;24:663-679,x.

97. Pellman EJ. Background on the National Football League's research on concussion in professional football. Neurosurgery 2003;53: 797-798

98. Purcell L, Carson J. Sport-related concussion in pediatric athletes Clin Pediatr (Phila) 2008;47:106-113.

99. Lee LK. Controversies in the sequelae of pediatric mild traumatic brain injury. Pediatr Emerg Care 2007;23:580-583; quiz 4-6.

100. Schnadower D, Vazquez H, Lee J, Dayan P, Roskind CG. Controversies in the evaluation and management of minor blunt head trauma in children. Curr Opin Pediatr 2007;19:258-264.

101. Wozniak JR, Krach L, Ward E, et al. Neurocognitive and neuroimaging correlates of pediatric traumatic brain injury: A diffusion tensor imaging (DTI) study. Arch Clin Neuropsychol 2007;22: $555-568$

102. Hayden MG, Jandial R, Duenas HA, Mahajan R, Levy M. Pediatric concussions in sports; a simple and rapid assessment tool for concussive injury in children and adults. Childs Nerv Syst 2007; 23:431-435.

103. Lee MA. Adolescent concussions-Management recommendations: $A$ practical approach. Conn Med 2006;70:377-380.

104. Kirkwood MW, Yeates KO, Wilson PE. Pediatric sport-related concussion: A review of the clinical management of an oft-neglected population. Pediatrics 2006;117:1359-1371.

105. Guskiewicz KM, Marshall SW, Bailes J, et al. Association between recurrent concussion and late-life cognitive impairment in retired professional football players. Neurosurgery 2005;57:719-726; discussion 726

106. Nandoe RD, Scheltens $P$, Eikelenboom P. Head trauma and Alzheimer's disease. J Alzheimers Dis 2002;4:303-308.

107. Stern MB. Head trauma as a risk factor for Parkinson's disease. Mov Disord 1991:6:95-97.

108. Omalu BI, DeKosky ST, Hamilton RL, et al. Chronic traumatic encephalopathy in a national football league player: Part II. Neurosurgery 2006;59:1086-1092; discussion 92-3.

109. Omalu BI, DeKosky ST, Minster RL, Kamboh MI, Hamilton RL, Wecht $\mathrm{CH}$. Chronic traumatic encephalopathy in a National Football League player. Neurosurgery 2005;57:128-134; discussion 134. 
110. McKee AC, Cantu RC, Nowinski CJ, et al. Chronic traumatic encephalopathy in athletes: Progressive tauopathy after repetitive head injury. J Neuropathol Exp Neurol 2009;68:709-735.

111. McKee AC, Gavett BE, Stern RA, et al. TDP-43 Proteinopathy and motor neuron disease in chronic traumatic encephalopathy. J Neuropathol Exp Neurol 2010;69;918-929.

112. McKee AC, Stein TD, Nowinski CJ, et al. The spectrum of disease in chronic traumatic encephalopathy. Brain 2013;136:43-64

113. McCrory P. Sports concussion and the risk of chronic neurological impairment. Clin J Sport Med 2011;21:6-12.

114. McCrory $P$. Future advances and areas of future focus in the treatment of sport-related concussion. Clin Sports Med 2011;30:201-208, xi-ii.

115. Hagel BE, Pless IB, Goulet C, Platt RW, Robitaille Y. Effectiveness of helmets in skiers and snowboarders: Case-control and case crossover study. BMJ 2005;330:281

116. McCrory $\mathrm{P}$. The role of helmets in skiing and snowboarding. $\mathrm{Br} \mathrm{J}$ Sports Med 2002;36:314.

117. Mueller BA, Cummings $P$, Rivara FP, Brooks MA, Terasaki RD. Injuries of the head, face, and neck in relation to ski helmet use. Epidemiology 2008;19:270-276.

118. Sulheim S, Holme I, Ekeland A, Bahr R. Helmet use and risk of head injuries in alpine skiers and snowboarders. JAMA 2006;295:919-924.

119. Delaney JS, Al-Kashmiri A, Drummond R, Correa JA. The effect of protective headgear on head injuries and concussions in adolescent football (soccer) players. Br J Sports Med 2008;42:110-115; discussion 5.

120. Viano DC, Pellman EJ, Withnall C, Shewchenko N. Concussion in professional football: Performance of newer helmets in reconstructed game impacts_-Part 13. Neurosurgery 2006;59:591-606; discussion 591-606

121. Finch C, Braham R, McIntosh A, McCrory P, Wolfe R. Should football players wear custom fitted mouthguards? Results from a group randomised controlled trial. Inj Prev 2005;11:242-246.

122. McIntosh $A, M c C r o r y ~ P$. The dynamics of concussive head impacts in rugby and Australian rules football. Med Sci Sports Exerc 2000;32:1980-1985.

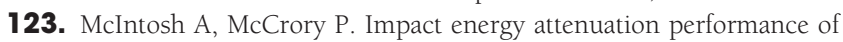
football headgear. Br J Sports Med 2000;34:337-342.

124. McIntosh A, McCrory $P$. Effectiveness of headgear in a pilot study of under 15 rugby union football. Br J Sports Med 2001;35:167-170.

125. McIntosh A, McCrory P, FInch C, Best J, Chalmers D. Rugby Headgear Study. J Sci Med Sport 2003;6:355-358.

126. Finch $C$, Newstead $S$, Cameron $M$, Vulcan $A$. Head injury reductions in Victoria two years after the introduction of mandatory bicycle helmet use. Report no. 51, July, 1993. Melbourne, Australia: Monash University Accident Research Centre; 1993.

127. Curnow WJ. Bicycle helmets and public health in Australia. Health Promot J Austr 2008;19:10-15.

128. Hewson PJ. Cycle helmets and road casualties in the UK. Traffic Inj Prev 2005;6:127-134

129. Davidson JA. Epidemiology and outcome of bicycle injuries presenting to an emergency department in the United Kingdom. Eur J Emerg Med 2005;12:24-29

130. Hansen KS, Engesaeter LB, Viste A. Protective effect of different types of bicycle helmets. Traffic Inj Prev 2003;4:285-290.

131. Andersen T, Arnason A, Engebretsen L, Bahr R. Mechanism of head injuries in elite football. Br J Sports Med 2004;38:690-696.

132. Hagel B, Meewisse W. Editorial: Risk compensation: A "Side effect" of sport injury prevention? Clin J Sport Med. 2004;14:193-196.

133. Finch $C$, Mcintosh AS, McCrory P, Zazryn T. A pilot study of the attitudes of Australian Rules footballers towards protective headgear. J Sci Med Sport 2003;6:505-511.

134. Finch CF, McIntosh AS, McCrory P. What do under 15 year old schoolboy rugby union players think about protective headgear? Br J Sports Med 2001;35:89-94.
135. Finch $C$, Mcintosh AS, McCrory $P$. What is the evidence base for the use of protective headgear and mouthguards in Australian football. Sport Health 2000;18:35-38.

136. Reece RM, Sege R. Childhood head injuries: Accidental or inflicted? Arch Pediatr Adolesc Med 2000;154:11-15.

137. Shaw NH. Bodychecking in hockey. CMAJ 2004;170:15-16; author reply 6,8 .

138. Denke NJ. Brain injury in sports. J Emerg Nurs 2008;34:363364.

139. Gianotti S, Hume PA. Concussion sideline management intervention for rugby union leads to reduced concussion claims. NeuroRehabilitation 2007;22:181-189.

140. Guilmette TJ, Malia LA, McQuiggan MD. Concussion understanding and management among New England high school football coaches. Brain Inj 2007;21:1039-1047.

141. Hootman JM, Dick R, Agel J. Epidemiology of collegiate injuries for 15 sports: Summary and recommendations for injury prevention initiatives. J Athl Train 2007;42:311-319

142. Valovich McLeod TC, Schwartz C, Bay RC. Sport-related concussion misunderstandings among youth coaches. Clin J Sport Med 2007;17: 140-142.

143. Sye G, Sullivan SJ, McCrory P. High school rugby players' understanding of concussion and return to play guidelines. Br J Sports Med 2006:40:1003-1005.

144. Theye F, Mueller KA. "Heads up": Concussions in high school sports. Clin Med Res 2004:2:165-171

145. Kashluba S, Paniak C, Blake T, Reynolds S, Toller-Lobe G, Nagy J. A longitudinal, controlled study of patient complaints following treated mild traumatic brain injury. Arch Clin Neuropsychol 2004;19:805816.

146. Gabbe B, Finch CF, Wajswelner H, Bennell K. Does community-level Australian football support injury prevention research? J Sci Med Sport 2003;6:231-236

147. Kaut KP, DePompei R, Kerr J, Congeni J. Reports of head injury and symptom knowledge among college athletes: Implications for assessment and educational intervention. Clin J Sport Med 2003;13:213221

148. Davidhizar $R$, Cramer $C$. "The best thing about the hospitalization was that the nurses kept me well informed" Issues and strategies of client education. Accid Emerg Nurs 2002;10:149-154.

149. McCrory $\mathrm{P}$. What advice should we give to athletes postconcussion? Br J Sports Med 2002;36:316-318

150. Bazarian JJ, Veenema $T$, Brayer AF, Lee E. Knowledge of concussion guidelines among practitioners caring for children. Clin Pediatr (Phila) 2001:40:207-212.

151. Guskiewicz KM, Weaver NL, Padua DA, Garrett WE Jr. Epidemiology of concussion in collegiate and high school football players. Am J Sports Med 2000;28:643-650.

152. McCrea M, Guskiewicz KM, Marshall SW, et al. Acute effects and recovery time following concussion in collegiate football players: The NCAA Concussion Study. JAMA 2003;290:2556-2563.

153. Macciocchi SN, Barth JT, Alves W, Rimel RW, Jane JA. Neuropsychological functioning and recovery after mild head injury in collegiate athletes. Neurosurgery 1996;39:510-514.

154. Meehan WP III, d'Hemecourt P, Comstock RD. High school concussions in the 2008-2009 academic year: Mechanism, symptoms, and management. Am J Sports Med 2010;38:2405-2409.

155. Eckner JT, Kutcher JS, Richardson JK. Between-seasons test-retest reliability of clinically measured reaction time in National Collegiate Athletic Association Division I athletes. J Athl Train 2011;46:409-414.

156. Eckner JT, Richardson JK, Kim H, Lipps DB, Ashton-Miller JA. A novel clinical test of recognition reaction time in healthy adults. Psychol Assess 2012;24:249-254. 
Footnotes Continued From Page 255.

\section{Writing Group}

P.M. Associate Professor, The Florey Institute of Neuroscience and Mental Health, Heidelberg, Australia. Address correspondence to: P.M.; e-mail:

Author affiliations can be found on page 269.

Disclosure: co-investigator, collaborator, consultant on grants relating to mild TBI funded by several governmental organizations; co-chair, Australian Centre for Research into Sports Injury and its Prevention, one of the International Research Centres for Prevention of Injury and Protection of Athlete Health supported by the International Olympic Committee; clinical and consulting practice in general and sports neurology; receives book royalties, McGraw-Hill; employed in an editorial capacity, British Medical Journal Publishing Group, 2001-2008; reimbursed by the government, professional scientific bodies, and sporting bodies for presenting research relating to mild TBI and sport-related concussion at meetings, scientific conferences, and symposiums; received consultancy fees, 2010, Axon Sports (US) for development of educational material (which was not renewed); received research funding since 2005, CogState Inc.; cofounder and shareholder in 2 biomedical companies (involved in eHealth and Compression garment technologies) but does not hold any individual shares in any company related to concussion or brain injury assessment or technology. He did not receive any form of financial support directly related to this manuscript.

W.H.M. Professor and Co-chair, Sport Injury Prevention Research Centre, Faculty of Kinesiology and Hotchkiss Brain Institute, Faculty of Medicine, University of Calgary, Calgary, Alberta, Canada

Disclosure: received research grant support, University of Calgary from the Canadian Institutes of Health Research, Alberta Innovates Health Solutions, the International Football Association (FIFA), Alberta Children's Hospital Research Institute, and the Hotchkiss Brain Institute; co-chair, Sport Injury Prevention Research Centre, one of the International Research Centres for Prevention of Injury and Protection of Athlete Health supported by the International Olympic Committee; clinical and consulting practice in sport medicine, University of Calgary Sport Medicine Centre, focus on sport related concussion; received travel funding, FIFA and the Medical Commission of the IOC; editor-in-chief, 1998-2012, Clinical Journal of Sport Medicine and received editorial support funding, Lippincott-Wolters Kluwer; receives compensation as a medical consultant, National Hockey League; may receive royalty, BKIN Technologies; shareholder, Safebrain Canada and PrivIT Healthcare. He did not receive any form of financial support directly related to this manuscript.

M.A. Chief Medical Officer, International Ice Hockey Federation, Switzerland; Member of the IOC Medical Commission Games Group; Co-director, Ottawa Sport Medicine Centre, Ottawa, Ontario, Canada

Disclosure: receives travel funding, IIHF and IOC Medical Commission Games Group for meetings, IIHF Championships, and Olympic Games. He did not receive any form of financial support directly related to this manuscript.

R.C.C. Clinical Professor, Neurosurgery and Co-director, Center for the Study of Traumatic Encephalopathy, Boston University Medical Center, Boston, MA

Disclosure: vice president, National Operating Committee on Standards for Athletic Equipment; co-founder and chairman medical director, Sports Legacy, Waltham, MA, USA; senior advisor, NFL's Head, Neck and Spine Committee; expert witness, trial testimony. He did not receive any form of financial support directly related to this manuscript

J.D. Professor of Neurology, University of Zurich; Senior Consultant, Schulthess Clinic Zurich, Switzerland; Chairman F-MARC (FIFA Medical Assessment and Research Center) Zurich Switzerland

Disclosure: received compensation, chief medical officer, FIFA. No other compensations or grants have been received. He did not receive any form of financial support directly related to this manuscript.

R.J.E. Psychological and Neurobehavioral Associates, Inc, State College, PA, USA; Adjunct Associate Professor of Psychology, University of Missouri, Kansas City, MO, USA Disclosure: receives financial compensation, consultant, National Hockey League, Major League Soccer, and the U.S. Soccer Federation; receives financial compensation, consultant, Princeton University; served as PI or co-PI on grants, NOCSAE, AMSSM, and the New Jersey Commission on Brain Injury Research; maintains a private practice focused on clinical neuropsychology, sports neuropsychology, and forensic applications of neuropsychology. He did not receive any form of financial support directly related to this manuscript.
L.E. Professor, Department of Orthopaedic Surgery, Oslo University Hospital and Faculty of Medicine, University of Oslo, Norway; Co-chair, Oslo Sports Trauma Research Center, Oslo, Norway; Head, Scientific Activities, International Olympic Committee (IOC), Lausanne Switzerland

Disclosure: received research grant support, University of Oslo from the Norwegian Institutes of Health Research, The Health South East, the International Football Association; co-chair, Sport Injury Prevention Research Centre, one of the International Research Centres for Prevention of Injury and Protection of Athlete Health supported by the International Olympic Committeel; professor and chair, Oslo University Orthopedic department; 2008-present, editor-in-chief, BJSM IPHP; January 2012-present, coeditor, The Journal of Bone and Joints. He did not receive any form of financial support directly related to this manuscript.

K.M.J. Neurosurgeon, Division of Neurosurgery, University of Toronto; Concussion Management Program, Athletic Edge Sports Medicine, Toronto, Canada

Disclosure: neurosurgeon subspecialized in brain trauma; clinical and research focus in sport concussion; received research funding through the CIHR, ONF, and Innovation Fund, American College of Surgeons, McGill University, Pashby Sport Safety Fund, and Think First Canada; independent consultant, many sport organizations. She has never had a formal reimbursed affiliation with any sport team or sport governing body. She did not receive any form of financial support directly related to this manuscript.

J.S.K. Associate Professor and Director, Michigan NeuroSport, Department of Neurology, University of Michigan, Ann Arbor, MI, USA

Disclosure: director, Michigan NeuroSport, University of Michigan's academic sports neurology program; received research grant support, National Collegiate Athletic Association and EIMindA, Ltd.; director, National Basketball Association's Concussion Program; paid consultant, National Hockey League Players' Association; current member, National Football League Players' Association's Mackey-White TBI Committee, consulting neurologist, United States Ski and Snowboard Association; founding member and the first chairperson, Sports Neurology Section of the American Academy of Neurology. He did not receive any form of financial support directly related to this manuscript.

M.R. Chief Medical Officer, International Rugby Board, Dublin, Ireland Disclosure: nothing to disclose

A.S. Associate Professor, Neurosurgery, Orthopaedic Surgery and Rehabilitation; Vanderbilt Sports Concussion Center, Vanderbilt University Medical Center, Nashville, TN, USA

Disclosure: medical board, received travel funding, Federation Equestrian Internationale; unpaid neurosurgical consultant, US Equestrian Foundation, the Southeastern Conference Working Group on Concussion, and Nashville Predators (NHL) hockey team; clinical practice in neurosurgery, Vanderbilt University Medical Center, with a focus on neurological problems in athletes. He did not receive any form of financial support directly related to this manuscript

B.W.B. Adjunct Research Assistant Professor, Department of Clinical Neurosciences, Faculty of Medicine; Clinical Assistant Professor, Department of Family Medicine, Sport Medicine Centre, Faculty of Kinesiology, University of Calgary, Calgary, Alberta, Canada Disclosure: clinical and consulting practice, sport medicine, University of Calgary Sport Medicine Centre with a focus on sport-related concussion; director, Sport Concussion Clinic at the University of Calgary Sport Medicine Centre; may receive royalty from BKIN Technologies. He did not receive any form of financial support directly related to this manuscript.

G.A.D. Department of Neurosurgery, Austin and Cabrini Hospitals and The Florey Institute of Neuroscience and Mental Health, Melbourne, Victoria, Australia Disclosure: received travel funding, FIFA. He did not receive any form of financial support directly related to this manuscript

R.E. Professor and Chairman, Theodore S. Roberts Endowed Chair, Department of Neurological Surgery, University of Washington Seattle, WA. USA; Cochair, NFL Head, Neck and Spine Medical Committee

Disclosure: nothing to disclose

K.M.G. Kenan Distinguished Professor and Chair, Department of Exercise and Sport Science; Co-director, Matthew Geller Sport-Related Traumatic Brain Injury Research Center, University of North Carolina at Chapel Hill, Chapel Hill, NC, USA

Disclosure: serves on NCAA's Health and Safety Advisory Committee for Concussion, NFL's Head Neck and Spine Committee, and NFLPA's Mackey-White Committee; received funding for travel and honoraria for lectures on sports concussion for professional organizations, including the IOC and FIFA; expert testimony, traumatic brain 
injury/concussion cases; received research funding, National Institutes of Health, Centers for Disease Control and Prevention, National Operating Committee for Standards in Athletic Equipment, National Collegiate Athletic Association, NFL Charities, NFL Players' Association, USA Hockey, and National Athletic Trainers' Association. He did not receive any form of financial support directly related to this manuscript.

S.A.H. Clinical Professor, Departments of Rehabilitation Medicine, Orthopaedics, and Sports Medicine and Neurological Surgery, University of Washington; Co-Medical Director, Seattle Sports Concussion Program; Team Physician, Seattle Seahawks and Seattle Mariners, Seattle, WA, USA

Disclosure: member, National Football League Head, Neck and Spine Committee; member, Football and Wellness Committee USA Football; member, Medical Advisory Board Pop Warner Football; chair, Medical Advisory Board X2IMPACT, a non-financial position; clinical and consulting practice, Harborview Medical Center focusing on the diagnosis and management of neurological and musculoskeletal injuries with particular interest in spinal disorders in active people and athletes and sports-related concussions. No form of financial support directly related to this manuscript was received.

G.L.I. Neuropsychology Outcome Assessment Laboratory; Professor, Department of Psychiatry, University of British Columbia, Vancouver, BC, Canada

Disclosure: reimbursed by government, professional scientific bodies, and commercial organizations for discussing or presenting research relating to mild TBI and sport-related concussion at meetings, scientific conferences, and symposiums; clinical and consulting practice in forensic neuropsychology involving individuals who have sustained mild TBIs (including professional athletes); received research funding from several test publishing companies, including ImPACT Applications, Inc., CNS Vital Signs, and Psychological Assessment Resources (PAR, Inc.). He did not receive any form of financial support directly related to this manuscript.

B.D.J. Associate Professor, Clinical Neurology at Weill Medical College of Cornell University. New York, NY, USA; Assistant Medical Director, Burke Rehabilitation Hospital, White Plains, NY, USA; Chief Medical Officer, New York State Athletic Commission, New York, NY, USA

Disclosure: financial compensation, National Football League (NFL) Benefits Association for the establishment of Neurocognitive Disability Benefit for retired players; financial compensation, Innovative CEUs, developing a medical-based high school coaching education program; as the CMO of New York State Athletic Commission, is a governor's appointed public officer of the State of New York; maintains an inpatient and outpatient clinical practice, Burke Rehabilitation Hospital specializing in traumatic brain injury, dementia, and sports neurology; National Football League Players Association MackeyWhite Traumatic Brain Injury Committee. Dr. Jordan did not receive any financial support related to this manuscript.

J.K. Sport Medicine Physician, Ottawa Sport Medicine Centre, Ottawa, Canada; Clinical Lecturer, Department of Family Medicine, University of Ottawa, Ottawa, Canada; Team Physician, Canadian National Men's Sledge Hockey Team

Disclosure: clinical and consulting practice in sport and exercise medicine, Ottawa Sport Medicine Centre. He did not receive any form of financial support directly related to this manuscript.

M. McCrea Professor and Director, Brain Injury Research, Departments of Neurosurgery and Neurology, Medical College of Wisconsin, WI, USA

Disclosure: funded, United States Department of Defense, U.S. Defense Veterans Brain Injury Center, NFL Charities, National Collegiate Athletic Association, National Operating Committee on Standards for Athletic Equipment, National Federation of High School Associations, and other funding organizations (past decade); member, NFL Head, Neck and Spine Committee; served on several U.S. national panels for scientific review and policy making relevant to sport-related concussion; funded by BrainScope, Inc. for prior studies, but receives no direct compensation from BrainScope or other industry entities/sports organizations; co-author, Standardized Assessment of Concussion (receives no financial compensation or support from publication or distribution of the SAC); PI on a study by the U.S. Department of Defense comparing several computerized neurocognitive assessment tools for the assessment of sport-related concussion. He did not receive any form of financial support directly related to this manuscript.

A.S.M. Adjunct Associate Professor, Australian Centre for Research into Injury in Sports and its Prevention, Monash Injury Research Institute, Monash University; Adjunct Associate Professor, Transport and Road Safety Research, Faculty of Science, the University of New South Wales; Director, McIntosh Consultancy and Research Pty Ltd., Sydney, Australia
Disclosure: self-employed consultant; has received grant support through UNSW from the Australian Research Council, NSW Racing, the IRB, the ARU, and the AFL; consultant, sport and sports injury, including the Australian Racing Board, McLaren Fl, the IRB, and Albion; received travel funding, International Rugby Board, IIHF, FIFA, the Medical Commission of the IOC. He did not receive any form of financial support directly related to this manuscript.

D.L.M. Barrister and Solicitor, Perry Maddocks Trollope Lawyers, Melbourne, Australia. Neuropsychologist in private practice

Disclosure: received research grant support, Australian Football League (AFL); provides consultancy medico-legal advice, AFL; received travel funding, FIFA. He did not receive any form of financial support directly related to this manuscript.

M. Makdissi Research Fellow, The Florey Institute of Neuroscience and Mental Health, Melbourne Brain Centre, Austin Campus, Melbourne, Australia; Research Fellow, Centre for Health Exercise and Sports Medicine, Melbourne Physiotherapy Department, University of Melbourne, Melbourne, Australia

Disclosure: received research grant support, The Florey Institute of Neurosciences and Mental Health from the National Health and Medical Research Council, the Australian Football League, and AFL Medical Officers Association; received travel funding, FIFA; clinical and consulting practice in sports medicine. He did not receive any form of financial support directly related to this manuscript.

L.P. Associate Clinical Professor, Department of Pediatrics, McMaster University, Hamilton, Ontario, Canada; Pediatric Sport Medicine Physician, David Braley Sport Medicine and Rehabilitation Centre, McMaster University, Hamilton, Ontario, Canada: President, Paediatric Sport and Exercise Medicine Section, CPS Disclosure: nothing to disclose

M.P. Director of Athletic Medicine, Head Team Physician, Princeton University; Associate Clinical Professor, Robert Wood Johnson, University of Medicine and Dentistry of New Jersey (UMDNJ), NJ, USA

Disclosure: received research grant support, New Jersey Commission on Brain Injury, the American Medical Society for Sports Medicine, and the National Operating Committee on Standards for Athletic Equipment; chair, US Lacrosse Sports Science \& Safety Committee; serves on the National Football League Head Neck and Spine Committee, chairing the Return to Play subcommittee, NFL; team physician, Princeton University; team physician, US Men's National Lacrosse Team and US Soccer; consultant, concussion, Center for Disease Controls and National Collegiate Athletic Association; past president, AMSSM; president, AMSSM Foundation. Dr. Putukian does not receive any financial compensation for her work with the AMSSM, NFL, US Lacrosse, CDC or NCAA. She did not receive any form of financial support directly related to this manuscript.

K.S. Sport Injury Prevention Research Centre, Faculty of Kinesiology, University of Calgary, Calgary, Alberta, Canada

Disclosure: research grant support, University of Calgary from the Alberta Centre for Child, Family and Community Research; clinical and consulting practice in physiotherapy, Evidence Sport and Spinal and Centric Health with a focus on sport related concussion. She did not receive any form of financial support directly related to this manuscript.

C.H.T. Professor of Neurosurgery, Toronto Western Hospital and University of Toronto, Canada; Senior Scientist, Krembil Neuroscience Centre, Toronto, Canada; Founder, ThinkFirst Canada; Board Member, Parachute Canada

Disclosure: consultant, ImpaKt Protective; co-chair, Concussion Awareness and Recognition Committee of the Ontario Neurotrauma Foundation, chair, ThinkFirst's Concussion Education and Awareness Committee; project director, Canadian Sports Concussion Project, Krembil Neuroscience Centre; director, Ontario Concussion Centres Consortium; received research grants, public sources including Canadian Institute for Health Research, and Ontario Brain Institute. He did not receive any financial support related to this manuscript.

M.T. Chief Medical Adviser, British Horseracing Authority, London, United Kingdom Disclosure: chief medical advisor, British Horseracing Authority, Lawn Tennis Association; travel funding, FIFA, the IOC, the ACSM, and Gruppoforte (Physiomind), for attending conferences and lecturing; most conferences also provided free registration and support for accommodations. He did not receive any form of financial support directly related to this manuscript. 


\section{APPENDIX}

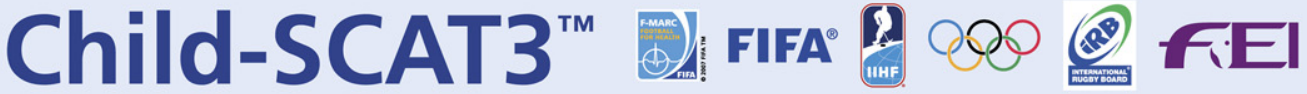

Sport Concussion Assessment Tool for children ages 5 to 12 years

For use by medical professionals only

\section{What is childSCAT3 ${ }^{1}$}

The ChildSCAT3 is a standardized tool for evaluating injured children for concussion and can be used in children aged from 5 to 12 years. It supersedes the original SCAT and the SCAT2 published in 2005 and 2009, respectively2. For older persons, ages 13 years and over, please use the SCAT3. The ChildSCAT3 is designed for use by medical professionals. If you are not
qualified, please use the Sport Concussion Recognition Tool'. Preseason baseline testing with the ChildSCAT3 can be helpful for interpreting post-injury test scores.

Specific instructions for use of the ChildSCAT3 are provided on page 3 . If you are not familiar with the ChildSCAT3, please read through these instructions carefully. This tool may be freely copied in its current form for distribution to individuals, teams, groups and organizations. Any revision and any reproduction in a digital form require approval by the Concussion in Sport Group.

NOTE: The diagnosis of a concussion is a clinical judgment, ideally made by a medical professional. The ChildSCAT3 should not be used solely to make, or exclude, the diagnosis of concussion in the ab-

\section{What is a concussion?}

A concussion is a disturbance in brain function caused by a direct or indirect force to the head. It results in a variety of non-specific signs and/or symptoms (like those listed below) and most often does not involve loss of consciousness. Concussion should be suspected in the presence of any one or more of the following:

-Symptoms (e.g., headache), or

- Physical signs (e.g. unsteadiness), or

- Impaired brain function (e.g. confusion) or

-Abnormal behaviour (e.g. change in personality).

\section{SIDELINE ASSESSMENT}

\section{Indications for Emergency Management}

NOTE: A hit to the head can sometimes be associated with a more severe brain injury. If the concussed child displays any of the following, then do not proceed with the ChildSCAT3; instead activate emergency procedures and urgent transportation to the nearest hospital:

- Glasgow Coma score less than 15

- Deteriorating mental status

- Potential spinal injury

- Progressive, worsening symptoms or new neurologic signs

- Persistent vomiting

Evidence of skull fracture

- Post traumatic seizures

- Coagulopathy

- History of Neurosurgery (eg Shunt)

Multiple injuries

1 Glasgow coma scale (GCS)

\section{Best eye response (E)}

No eye opening

Eye opening in response to pain

Eye opening to speech

Eyes opening spontaneously

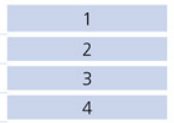

Best verbal response (V)

No verbal response

Incomprehensible sounds

Inappropriate words

Confused

Oriented

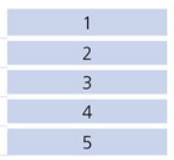

Best motor response (M)

No motor response

Extension to pain

Abnormal flexion to pain

Flexion/Withdrawal to pain

Localizes to pain

Obeys commands

Glasgow Coma score $(\mathrm{E}+\mathrm{V}+\mathrm{M})$

$G C S$ should be recorded for all athletes in case of subsequent deterioration.
Potential signs of concussion?

If any of the following signs are observed after a direct or indirect blow to the head, the child should stop participation, be evaluated by a medical professional and should not be permitted to return to sport the same day if a concussion is suspected.

Any loss of consciousness?

Y N

"If so, how long?"

Balance or motor incoordination (stumbles, slow/laboured movements, etc.)? $\quad$ Y N N Disorientation or confusion (inability to respond appropriately to questions)? $\quad \mathrm{Y} \quad \mathrm{N}$ Loss of memory:

"If so, how long?"

"Before or after the injury?"

Blank or vacant look:

Visible facial injury in combination with any of

2 Sideline Assessment - child-Maddocks Score ${ }^{3}$

"I am going to ask you a few questions, please listen carefully and give your best effort." Modified Maddocks questions (1 point for each correct answer)

Where are we at now?

Is it before or after lunch?

What did you have last lesson/class?

What is your teacher's name?

\begin{tabular}{|l|l|}
\hline 0 & 1 \\
\hline 0 & 1 \\
\hline 0 & 1 \\
\hline 0 & 1 \\
\hline
\end{tabular}

child-Maddocks score

of 4

Child-Maddocks score is for sideline diagnosis of concussion only and is not used for serial testing.

Any child with a suspected concussion should be REMOVED FROM PLAY, medically assessed and monitored for deterioration (i.e., should not be left alone). No child diagnosed with concussion should be returned to sports participation on the day of Injury.

\section{BACKGROUND}

\begin{tabular}{|c|c|c|}
\hline Name: & Date/Time of Injury: & \\
\hline Examiner: & Date of Assessment: & \\
\hline Sport/team/school: & & \\
\hline Age: & Gender: & M \\
\hline Current school year/grade: & & \\
\hline Dominant hand: & right left & neither \\
\hline
\end{tabular}

\section{For Parent/carer to complete:}

How many concussions has the child had in the past?

When was the most recent concussion?

How long was the recovery from the most recent concussion?

Has the child ever been hospitalized or had medical imaging done (CT or MRI) for a head injury?

Has the child ever been diagnosed with headaches or migraines? $\quad \mathrm{Y} N \mathrm{~N}$

Does the child have a learning disability, dyslexia, $\quad \mathrm{Y}$ N

ADD/ADHD, seizure disorder?

Has the child ever been diagnosed with depression, $\quad \mathrm{Y}$ N

anxiety or other psychiatric disorder?

Has anyone in the family ever been diagnosed with $\quad Y \quad N$

any of these problems?

Is the child on any medications? If yes, please list: $\quad$ Y 


\section{SYMPTOM EVALUATION}

\begin{tabular}{|c|c|c|c|c|}
\hline \multicolumn{5}{|l|}{ Child report } \\
\hline Name: & never & rarely & sometimes & often \\
\hline I have trouble paying attention & 0 & 1 & 2 & 3 \\
\hline I get distracted easily & 0 & 1 & 2 & 3 \\
\hline I have a hard time concentrating & 0 & 1 & 2 & 3 \\
\hline I have problems remembering what people tell me & 0 & 1 & 2 & 3 \\
\hline I have problems following directions & 0 & 1 & 2 & 3 \\
\hline I daydream too much & 0 & 1 & 2 & 3 \\
\hline I get confused & 0 & 1 & 2 & 3 \\
\hline I forget things & 0 & 1 & 2 & 3 \\
\hline I have problems finishing things & 0 & 1 & 2 & 3 \\
\hline I have trouble figuring things out & 0 & 1 & 2 & 3 \\
\hline It's hard for me to learn new things & 0 & 1 & 2 & 3 \\
\hline I have headaches & 0 & 1 & 2 & 3 \\
\hline I feel dizzy & 0 & 1 & 2 & 3 \\
\hline I feel like the room is spinning & 0 & 1 & 2 & 3 \\
\hline I feel like I'm going to faint & 0 & 1 & 2 & 3 \\
\hline Things are blurry when I look at them & 0 & 1 & 2 & 3 \\
\hline I see double & 0 & 1 & 2 & 3 \\
\hline I feel sick to my stomach & 0 & 1 & 2 & 3 \\
\hline I get tired a lot & 0 & 1 & 2 & 3 \\
\hline I get tired easily & 0 & 1 & 2 & 3 \\
\hline \multicolumn{5}{|l|}{ Total number of symptoms (Maximum possible 20 ) } \\
\hline self rated $\quad$ clinician interview & & and clinic & cian monitore & \\
\hline
\end{tabular}

\section{Parent report}

The child

has trouble sustaining attention

Is easily distracted

has difficulty concentrating

has problems remembering what he/she is told

has difficulty following directions

tends to daydream

gets confused

is forgetful

has difficulty completeing tasks

has poor problem solving skills

has problems learning

has headaches

feels dizzy

has a feeling that the room is spinning

feels faint

has blurred vision

has double vision

experiences nausea

gets tired a lot

gets tired easily

\begin{tabular}{|c|c|c|c|}
\hline never & rarely & sometimes & often \\
\hline 0 & 1 & 2 & 3 \\
\hline 0 & 1 & 2 & 3 \\
\hline 0 & 1 & 2 & 3 \\
\hline 0 & 1 & 2 & 3 \\
\hline 0 & 1 & 2 & 3 \\
\hline 0 & 1 & 2 & 3 \\
\hline 0 & 1 & 2 & 3 \\
\hline 0 & 1 & 2 & 3 \\
\hline 0 & 1 & 2 & 3 \\
\hline 0 & 1 & 2 & 3 \\
\hline 0 & 1 & 2 & 3 \\
\hline 0 & 1 & 2 & 3 \\
\hline 0 & 1 & 2 & 3 \\
\hline 0 & 1 & 2 & 3 \\
\hline 0 & 1 & 2 & 3 \\
\hline 0 & 1 & 2 & 3 \\
\hline 0 & 1 & 2 & 3 \\
\hline 0 & 1 & 2 & 3 \\
\hline 0 & 1 & 2 & 3 \\
\hline 0 & 1 & 2 & 3 \\
\hline
\end{tabular}

Total number of symptoms (Maximum possible 20)

Symptom severity score (Maximum possible 20 $\times 3=60$ )

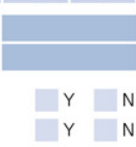

Do the symptoms get worse with physical activity?

Do the symptoms get worse with mental activity?

parent self rated clinician interview parent self rated and clinician monitored Overall rating for parent/teacher/coach/carer to answer.

How different is the child acting compared to his/her usual self? Please circle one response:

\begin{tabular}{|l|l|l|l|}
\hline no different & very different & unsure & N/A \\
\hline
\end{tabular}

Name of person completing Parent-report:

Relationship to child of person completing Parent-report:

Scoring on the ChildSCAT3 should not be used as a stand-alone method to diagnose concussion, measure recovery or make decisions about an athlete's readiness to return to competition after concussion.

\section{COGNITIVE \& PHYSICAL EVALUATION}

5 Cognitive assessment

Standardized Assessment of Concussion - Child Version (SAC-C)

Orientation (1 point for each correct answer)

What month is it?

What is the date today?

What is the day of the week?

What year is it?

Orientation score

\begin{tabular}{|l|l|}
\hline 0 & 1 \\
\hline 0 & 1 \\
\hline 0 & 1 \\
\hline 0 & 1 \\
\hline
\end{tabular}

Immediate memory

\begin{tabular}{l|l|l|l|l}
\hline List & Trial 1 & Trial 2 & Trial 3 & Alternative word list
\end{tabular}

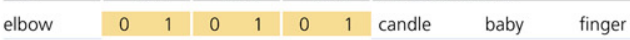

\begin{tabular}{l|ll|ll|ll|l|l|l|l} 
apple & 0 & 1 & 0 & 1 & 0 & 1 & paper monkey penny
\end{tabular}

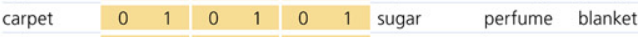

\begin{tabular}{l|ll|ll|ll|l|l|l} 
saddle & 0 & 1 & 0 & 1 & 0 & 1 & sandwich sunset lemon
\end{tabular}

\begin{tabular}{l|ll|ll|ll|l|l|l} 
bubble & 0 & 1 & 0 & 1 & 0 & 1 & wagon insect
\end{tabular}

Total

Immediate memory score total

Concentration: Digits Backward

\begin{tabular}{l||l|l}
\hline List & Trial 1 Alternative digit list
\end{tabular}

\begin{tabular}{l|ll|l|l|l}
$6-2$ & 0 & 1 & $5-2$ & $4-1$ & $4-9$
\end{tabular}

\begin{tabular}{l|ll|lll}
$4-9-3$ & 0 & 1 & $6-2-9$ & $5-2-6$ & $4-1-5$
\end{tabular}

\begin{tabular}{l|ll|l|l|l}
$3-8-1-4$ & 0 & 1 & $3-2-7-9$ & $1-7-9-5$ & $4-9-6-8$
\end{tabular}

\begin{tabular}{l|lllll}
$6-2-9-7-1$ & 0 & 1 & $1-5-2-8-6$ & $3-8-5-2-7$ & $6-1-8-4-3$
\end{tabular}

\begin{tabular}{l|lllll}
$7-1-8-4-6-2$ & 0 & 1 & $5-3-9-1-4-8$ & $8-3-1-9-6-4$ & $7-2-4-8-5-6$
\end{tabular}

Total of 5

Concentration: Days in Reverse Order (1 pt. for entire sequence correct)

Sunday-Saturday-Friday-Thursday-Wednesday-

Tuesday-Monday

Concentration score

6 Neck Examination:

Range of motion Tenderness Upper and lower limb sensation \& strength Findings:

\section{Balance examination}

Do one or both of the following tests.

Footwear (shoes, barefoot, braces, tape, etc.)

Modified Balance Error Scoring System (BESS) testing ${ }^{5}$

Which foot was tested (i.e. which is the non-dominant foot) Left Right

Testing surface (hard floor, field, etc.

Condition

Double leg stance:

Tandem gait ${ }^{6,7}$

Time taken to complete (best of 4 trials): seconds

If child attempted, but unable to complete tandem gait, mark here

8 Coordination examination

Upper limb coordination

Which arm was tested:

Left Right

Coordination score

of 1

9 SAC Delayed Recall ${ }^{4}$

Delayed recall score

Since signs and symptoms may evolve over time, it is important to consider repeat evaluation in the acute assessment of concussion. 


\section{INSTRUCTIONS}

Words in Italics throughout the ChildSCAT3 are the instructions given to the child by the tester.

\section{Sideline Assessment - child-Maddocks Score}

To be completed on the sideline/in the playground, immediately following concussion. There is no requirement to repeat these questions at follow-up.

\section{Symptom Scale ${ }^{8}$}

In situations where the symptom scale is being completed after exercise, it should still be done in a resting state, at least 10 minutes post exercise.

On the day of injury

the child is to complete the Child Report, according to how he/she feels now. On all subsequent days

- the child is to complete the Child Report, according to how he/she feels today, and

the parent/carer is to complete the Parent Report according to how the child has been over the previous 24 hours.

\section{Standardized Assessment of Concussion - Child Version (SAC-C)}

Orientation

Ask each question on the score sheet. A correct answer for each question scores 1 point. If the child does not understand the question, gives an incorrect answer, or no answer, then the score for that question is 0 points.

Immediate memory

am going to test your memory I will read you a list of words and when I am done, repeat back as many words as you can remember, in any order."

Trials 2\&3:

lam going to repeat the same list again. Repeat back as many words as you can remember in any order, even if you said the word before."

Complete all 3 trials regardless of score on trial 1 \&2. Read the words at a rate of one per second. Score 1 pt. for each correct response. Total score equals sum across all 3 trials. Do not inform Score $1 \mathrm{pt}$. for each correct response.
the child that delayed recall will be tested.

Concentration

Digits Backward:

I am going to read you a string of numbers and when I am done, you repeat them back to me backwards, in reverse order of how I read them to you. For example, if I say 7-1, you would say 1-7,"

if correct, go to next string length. If incorrect, read trial 2. One point possible for each string length. Stop after incorrect on both trials. The digits should be read at the rate of one per second.

Days in Reverse Order:

"Now tell me the days of the week in reverse order. Start with Sunday and go backward. So you'll say Sunday, Saturday.... Go ahead"

$1 \mathrm{pt}$. for entire sequence correct

Delayed recall

The delayed recall should be performed after completion of the Balance and Coordination Examination.

Do you remember that list of words I read a few times earlier? Tell me as many words from the list as you can remember in any order."

Circle each word correctly recalled. Total score equals number of words recalled.

\section{Balance examination}

These instructions are to be read by the person administering the childSCAT3, and each balance task should be demonstrated to the child. The child should then be asked to copy what the examiner demonstrated.

\section{Modified Balance Error Scoring System (BESS) testing ${ }^{5}$}

This balance testing is based on a modified version of the Balance Error Scoring System (BESS) $)^{5}$. A stopwatch or watch with a second hand is required for this testing. "I am now going to test your balance. Please take your shoes off, roll up your pant legs above ankle (if applicable), and remove any ankle taping (if applicable). This test will consist of two different parts."

\section{(a) Double leg stance:}

The first stance is standing with the feet together with hands on hips and with eyes closed. The child should try to maintain stability in that position for 20 seconds. You should inform the child lll be counting the number of tim tart timing when the child is set and the eyes are closed.

\section{(b) Tandem stance:}

instruct the child to stand heel-to-toe with the non-dominant foot in the back. Weight should be evenly distributed across both feet. Again, the child should try to maintain stability for 20 seconds with hands on hips and eyes closed. You should inform the child that you will be counting the number of times the child moves out of this position. If the child stumbles out of this position, instruct him/her to open the eyes and return to the start position and continue balancing. You should start timing when the child is set and the eyes are closed.
Balance testing - types of errors - Parts (a) and (b)

1. Hands lifted off iliac crest

2. Opening eyes

3. Step, stumble, or fall

4. Moving hip into $>30$ degrees abduction

5. Lifting forefoot or heel

6. Remaining out of test position $>5 \mathrm{sec}$

Each of the 20-second trials is scored by counting the errors, or deviations from the proper stance, accumulated by the child. The examiner will begin counting errors only after the child has assumed the proper start position. The modified BESS is calculated by adding one error point for each error during the two 20-5econd tests. The maximum total number of errors for any single condition is 10. If a child commits multiple errors simultaneously, only one error is recorded but the child should quickly return to the testing position, and counting should resume once subject is set. Children who are unable to maintain the testing procedure for a minimum of five seconds at the start are assigned the highest possible score, ten, for that testing condition.

OPTION: For further assessment, the same 2 stances can be performed on a surface of medium density foam (e.g., approximately $50 \mathrm{~cm} \times 40 \mathrm{~cm} \times 6 \mathrm{~cm}$ ).

\section{Tandem Gait ${ }^{6,7}$}

Use a clock (with a second hand) or stopwatch to measure the time taken to complete this task. Instruction for the examiner - Demonstrate the following to the child:

The child is instructed to stand with their feet together behind a starting line (the test is best done with footwear removed). Then, they walk in a forward direction as quickly and as accurately as possible along a $38 \mathrm{~mm}$ wide (sports tape), 3 meter line with an alternate foot heel-totoe gait ensuring that they approximate their heel and toe on each step. Once they cross the end of the $3 m$ line, they turn 180 degrees and return to the starting point using the same gait. A total of 4 trials are done and the best time is retained. Children fail the test tif they step ort the line, havea separation between theirheel and toe, or they touch or grab the exa Explain to the child that you will time how long it takes them to walk to the end of the line and back.

\section{Coordination examination}

\section{Upper limb coordination}

Finger-to-nose (FTN) task:

\section{The tester should demonstrate it to the child.}

"I am going to test your coordination now. Please sit comfortably on the chair with your eyes open and your arm (either right or left) outstretched (shoulder flexed to 90 degrees and elbow and fingers extended). When I give a start signal, I would hike you to perform five successive finger to nose repetitions

Scoring: 5 correct repetitions in $<4$ seconds $=1$

Note for testers: Children fail the test if they do not touch their nose, do not fully extend their elbow or do not perform five repetitions. Failure should be scored as 0 .

\section{References \& Footnotes}

1. This tool has been developed by a group of international experts at the 4 th International Consensus meeting on Concussion in Sport held in Zurich, Switzerland in November 2012. The full details of the conference outcomes and the authors of the tool are published in The BJSM Injury Prevention and Health Protection, 2013, Volume 47 , Issue 5 . The outcome paper will also be simultaneously co-published in other leading biomedical journals with the copyright held by the Concussion in Sport Group, to allow unrestricted distribution, providing no alterations are made.

2. McCrory P et al., Consensus Statement on Concussion in Sport - the 3rd International Conference on Concussion in Sport held in Zurich, November 2008. British Journal of Sports Medicine 2009; 43: i76-89.

3. Maddocks, DL; Dicker, GD; Saling, MM. The assessment of orientation following concussion in athletes. Clinical Journal of Sport Medicine. 1995; 5(1): 32-3.

4. McCrea M. Standardized mental status testing of acute concussion. Clinical Journal of Sport Medicine. 2001; 11: 176-181.

5. Guskiewicz KM. Assessment of postural stability following sport-related concussion. Current Sports Medicine Reports. 2003; 2: 24-30.

6. Schneiders, A.G., Sullivan, S.J., Gray, A., Hammond-Tooke, G.\&McCrory, P. Normative values for 16-37 year old subjects for three clinical measures of motor performance used in the assessment of sports concussions. Journal of Science and Medicine in Sport. 2010; 13(2): 196-201.

7. Schneiders, A.G., Sullivan, S.J., Kvarnstrom. J.K., Olsson, M., Yden. T. \& Marshall, S.W. The effect of footwear and sports-surface on dynamic neurological screening in sport-related concussion. Journal of Science and Medicine in Sport. 2010; 13(4): 382-386

8. Ayr, L.K., Yeates, K.O., Taylor, H.G., \& Brown, M. Dimensions of post-concussive symptoms in children with mild traumatic brain injuries. Journal of the International Neuropsychological Society. 2009; 15:19-30 


\section{CHILD ATHLETE INFORMATION}

Any child suspected of having a concussion should be removed from play, and then seek medical evaluation. The child must NOT return to play or sport on the same day as the suspected concussion.

\section{Signs to watch for}

Problems could arise over the first 24-48 hours. The child should not be left alone and must go to a hospital at once if they develop any of the following:

- New Headache, or Headache gets worse

- Persistent or increasing neck pain

- Becomes drowsy or can't be woken up

- Can not recognise people or places

- Has Nausea or Vomiting

- Behaves unusually, seems confused, or is irritable

- Has any seizures (arms and/or legs jerk uncontrollably)

- Has weakness, numbness or tingling (arms, legs or face)

- Is unsteady walking or standing

- Has slurred speech

- Has difficulty understanding speech or directions

\section{Remember, it is better to be safe.}

Always consult your doctor after a suspected concussion.

\section{Return to school}

Concussion may impact on the child's cognitive ability to learn at school. This must be considered, and medical clearance is required before the child may return to school. It is reasonable for a child to miss a day or two of school after concussion, but extended absence is uncommon. In some children, a graduated return to school program will need to be developed for the child. The child will progress through the return to school program provided that there is no worsening of symptoms. If any particular activity worsens symptoms, the child will abstain from that activity until it no longer causes symptom worsening. Use of computers and internet should follow a similar graduated program, provided that it does not worsen symptoms. This program should include communication between the parents, teachers, and health professionals and will vary from child to child. The return to school program should consider:

- Extra time to complete assignments/tests

- Quiet room to complete assignments/tests

- Avoidance of noisy areas such as cafeterias, assembly halls, sporting events,

music class, shop class, etc

- Frequent breaks during class, homework, tests

- No more than one exam/day

- Shorter assignments

- Repetition/memory cues

- Use of peer helper/tutor

- Reassurance from teachers that student will be supported through recovery

through accommodations, workload reduction, alternate forms of testing

- Later start times, half days, only certain classes

The child is not to return to play or sport until he/she has successfully returned to school/learning, without worsening of symptoms. Medical clearance should be given before return to play.

If there are any doubts, management should be referred to a qualified health practitioner, expert in the management of concussion in children.

\section{Return to sport}

There should be no return to play until the child has successfully returned to school/learning, without worsening of symptoms.

Children must not be returned to play the same day of injury.

When returning children to play, they should medically cleared and then follow a stepwise supervised program, with stages of progression.

\section{For example:}

\begin{tabular}{|c|c|c|}
\hline $\begin{array}{l}\text { Rehabilitation } \\
\text { stage }\end{array}$ & $\begin{array}{l}\text { Functional exercise at each stage } \\
\text { of rehabilitation }\end{array}$ & $\begin{array}{l}\text { Objective of } \\
\text { each stage }\end{array}$ \\
\hline No activity & Physical and cognitive rest & Recovery \\
\hline $\begin{array}{l}\text { Light aerobic } \\
\text { exercise }\end{array}$ & $\begin{array}{l}\text { Walking, swimming or stationary cycling } \\
\text { keeping intensity, } 70 \% \text { maximum pre- } \\
\text { dicted heart rate. No resistance training }\end{array}$ & Increase heart rate \\
\hline $\begin{array}{l}\text { Sport-specific } \\
\text { exercise }\end{array}$ & $\begin{array}{l}\text { Skating drills in ice hockey, running drills } \\
\text { in soccer. No head impact activities }\end{array}$ & Add movement \\
\hline $\begin{array}{l}\text { Non-contact } \\
\text { training drills }\end{array}$ & $\begin{array}{l}\text { Progression to more complex training } \\
\text { drills, eg passing drills in football } \\
\text { and ice hockey. May start progressive } \\
\text { resistance training }\end{array}$ & $\begin{array}{l}\text { Exercise, coordina- } \\
\text { tion, and cognitive } \\
\text { load }\end{array}$ \\
\hline $\begin{array}{l}\text { Full contact } \\
\text { practice }\end{array}$ & $\begin{array}{l}\text { Following medical clearance participate } \\
\text { in normal training activities }\end{array}$ & $\begin{array}{l}\text { Restore confidence } \\
\text { and assess functional } \\
\text { skills by coaching staff }\end{array}$ \\
\hline
\end{tabular}

There should be approximately 24 hours (or longer) for each stage and the child should drop back to the previous asymptomatic level if any post-concussive symptoms recur. Resistance training should only be added in the later stages. If the child is symptomatic for more than 10 days, then review by a health practitioner, expert in the management of concussion, is recommended. Medical clearance should be given before return to play.

\section{Notes:}

\section{CONCUSSION INJURY ADVICE FOR THE CHILD AND PARENTS / CARERS \\ (To be given to the person monitoring the concussed child)}

This child has received an injury to the head. A careful medical examination has been carried out and no sign of any serious complications has been found. It is expected that recovery will be rapid, but the child will need monitoring for the next 24 hours by a responsible adult.

If you notice any change in behavior, vomiting, dizziness, worsening headache, double vision or excessive drowsiness, please call an ambulance to transport the child to hospital immediately.

\section{Other important points:}

- Following concussion, the child should rest for at least 24 hours

- The child should avoid any computer, internet or electronic gaming activity if these activities make symptoms worse.

- The child should not be given any medications, including pain killers, unless prescribed by a medical practitioner.

- The child must not return to school until medically cleared.

- The child must not return to sport or play until medically cleared.

Patient's name

Date/time of injury

Date/time of medical review

Treating physician 


\section{Pocket CONCUSSION RECOGNITION TOOL ${ }^{\mathrm{TM}}$ To help identify concussion in children, youth and adults}

\section{FIFA}
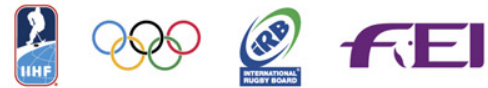

\section{RECOGNIZE \& REMOVE}

Concussion should be suspected if one or more of the following visible clues, signs, symptoms or errors in memory questions are present.

\section{Visible clues of suspected concussion}

Any one or more of the following visual clues can indicate a possible concussion:

Loss of consciousness or responsiveness

Lying motionless on ground/Slow to get up

Unsteady on feet / Balance problems or falling over/Incoordination

Grabbing/Clutching of head

Dazed, blank or vacant look

Confused/Not aware of plays or events

\section{Signs and symptoms of suspected concussion}

Presence of any one or more of the following signs \& symptoms may suggest a concussion:

$\begin{array}{ll}\text { - Loss of consciousness } & \text { - Headache } \\ \text { - Seizure or convulsion } & \text { - Dizziness } \\ \text { - Balance problems } & \text { - Confusion } \\ \text { - Nausea or vomiting } & \text { - Feeling slowed down } \\ \text { - Drowsiness } & \text { - "Pressure in head" } \\ \text { - More emotional } & \text { - Blurred vision } \\ \text { - Irritability } & \text { - Sensitivity to light } \\ \text { - Sadness } & \text { - Amnesia } \\ \text { - Fatigue or low energy } & \text { - Feeling like "in a fog" } \\ \text { - Nervous or anxious } & \text { - Neck Pain } \\ \text { - "Don't feel right" } & \text { - Sensitivity to noise } \\ \text { - Difficulty remembering } & \text { - Difficulty concentrating } \\ \text { O2013 concussion in Sport Group } & \end{array}$

\section{Memory function}

Failure to answer any of these questions correctly may suggest a concussion.

"What venue are we at today?"

"Which half is it now?"

"Who scored last in this game?"

"What team did you play last week/game?"

"Did your team win the last game?"

Any athlete with a suspected concussion should be IMMEDIATELY REMOVED FROM PLAY, and should not be returned to activity until they are assessed medically. Athletes with a suspected concussion should not be left alone and should not drive a motor vehicle.

It is recommended that, in all cases of suspected concussion, the player is referred to a medical professional for diagnosis and guidance as well as return to play decisions, even if the symptoms resolve.

\section{RED FLAGS}

If ANY of the following are reported then the player should be safely and immediately removed from the field. If no qualified medical professional is available, consider transporting by ambulance for urgent medical assessment:

Athlete complains of neck pain

Increasing confusion or irritability

- Repeated vomiting

Seizure or convulsion

-Weakness or tingling/burning in arms or legs

\section{Remember:}

- In all cases, the basic principles of first aid

(danger, response, airway, breathing, circulation) should be followed.

- Do not attempt to move the player (other than required for airway support)

unless trained to so do

- Do not remove helmet (if present) unless trained to do so.
Deteriorating conscious state

- Severe or increasing headache

- Unusual behaviour change

- Double vision 


\section{SCAT3 ${ }^{\text {m }}$}

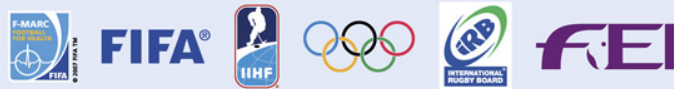

\section{Sport Concussion Assessment Tool - 3rd Edition}

For use by medical professionals only

\section{What is the SCAT3?}

The SCAT3 is a standardized tool for evaluating injured athletes for concussion and can be used in athletes aged from 13 years and older. It supersedes the original SCAT and the SCAT2 published in 2005 and 2009, respectively². For younge persons, ages 12 and under, please use the Child SCAT3. The SCAT3 is designed for use by medical professionals. If you are not qualified, please use the Spor Concussion Recognition Tool'. Preseason baseline testing with the SCAT3 can be helpful for interpreting post-injury test scores.

Specific instructions for use of the SCAT3 are provided on page 3. If you are not familiar with the SCAT3, please read through these instructions carefully. This tool may be freely copied in its current form for distribution to individuals, teams. groups and organizations. Any revision or any reproduction in a digital form requires approval by the Concussion in Sport Group.

NOTE: The diagnosis of a concussion is a clinical judgment, ideally made by a medical professional. The SCAT3 should not be used solely to make, or exclude, the diagnosis of concussion in the absence of clinical judgement. An athlete may have a concussion even if their SCAT3 is "normal".

What is a concussion?

A concussion is a disturbance in brain function caused by a direct or indirect force to the head. It results in a variety of non-specific signs and/or symptoms (some examples listed below) and most often does not involve loss of consciousness. Concussion should be suspected in the presence of any one or more of the following:

Symptoms (e.g., headache), or

- Physical signs (e.g., unsteadiness), or

Impaired brain function (e.g. confusion) or

Abnormal behaviour (e.g., change in personality).

\section{SIDELINE ASSESSMENT}

\section{Indications for Emergency Management}

NOTE: A hit to the head can sometimes be associated with a more serious brain injury. Any of the following warrants consideration of activating emergency procedures and urgent transportation to the nearest hospital:

Glasgow Coma score less than 15

- Deteriorating mental status

- Potential spinal injury

Progressive, worsening symptoms or new neurologic signs

Potential signs of concussion?

If any of the following signs are observed after a direct or indirect blow to the head, the athlete should stop participation, be evaluated by a medical professional and should not be permitted to return to sport the same day if a concussion is suspected.

Any loss of consciousness?

"If so, how long?"

Balance or motor incoordination (stumbles, slow/laboured movements, etc.)? $\square$ Y $\square \mathrm{N}$ Disorientation or confusion (inability to respond appropriately to questions)? $\quad \mathrm{Y}$ Loss of memory:

"If so, how long?"

"Before or after the injury?"

Blank or vacant look:

Visible facial injury in combination with any of the above:

\section{Glasgow coma scale (GCS)}

Best eye response (E)

No eye opening

Eye opening in response to pain

Eye opening to speech

Eyes opening spontaneously

\section{Best verbal response $(V)$}

No verbal response

Incomprehensible sounds

Inappropriate words

Confused

Oriented

\section{Best motor response $(\mathrm{M})$}

No motor response

Extension to pain

Abnormal flexion to pain

Flexion/Withdrawal to pain

Localizes to pain

Obeys commands

Glasgow Coma score $(\mathrm{E}+\mathrm{V}+\mathrm{M})$

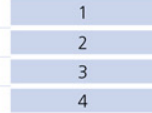

GCS should be recorded for all athletes in case of subsequent deterioration.

\section{Maddocks Score ${ }^{3}$}

"I am going to ask you a few questions, please listen carefully and give your best effort." Modified Maddocks questions (1 point for each correct answer)

What venue are we at today?

Which half is it now?

Who scored last in this match?

What team did you play last week/game?

Did your team win the last game?

\begin{tabular}{|l|}
\hline 1 \\
\hline 2 \\
\hline 3 \\
\hline 4 \\
\hline 5
\end{tabular}

\section{Maddocks score}

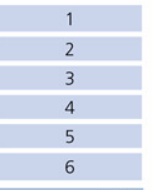

Maddocks score is validated for sideline diagnosis of concussion only and is not used for serial testing.

Notes: Mechanism of Injury ("tell me what happened"?):

Any athlete with a suspected concussion should be REMOVED FROM PLAY, medically assessed, monitored for deterioration (i.e., should not be left alone) and should not drive a motor vehicle until cleared to do so by a medical professional. No athlete diagnosed with concussion should be returned to sports participation on the day of Injury. 


\section{BACKGROUND}

Name:
Examiner:
Sport/team/school:
Age:
Years of education completed:
Dominant hand:
How many concussions do you think you have had in the past?
When was the most recent concussion?
How long was your recovery from the most recent concussion?
Have you ever been hospitalized or had medical imaging done for
a head injury?
Have you ever been diagnosed with headaches or migraines?
$\begin{aligned} & \text { Do you have a learning disability, dyslexia, ADD/ADHD? } \\ & \text { Have you ever been diagnosed with depression, anxiety } \\ & \text { or other psychiatric disorder? } \\ & \text { Has anyone in your family ever been diagnosed with } \\ & \text { any of these problems? } \\ & \text { Are you on any medications? If yes, please list: }\end{aligned}$

SCAT3 to be done in resting state. Best done 10 or more minutes post excercise.

\section{SYMPTOM EVALUATION}

\section{How do you feel?}

"You should score yourself on the following symptoms, based on how you feel now".

\begin{tabular}{l|l|l|l|l|l|l|l|}
\hline & none & \multicolumn{2}{|c|}{ mild } & \multicolumn{2}{|c|}{ moderate } & \multicolumn{2}{|c|}{ severe } \\
\hline Headache & 0 & 1 & 2 & 3 & 4 & 5 & 6 \\
\hline "Pressure in head" & 0 & 1 & 2 & 3 & 4 & 5 & 6 \\
\hline Neck Pain & 0 & 1 & 2 & 3 & 4 & 5 & 6 \\
\hline Nausea or vomiting & 0 & 1 & 2 & 3 & 4 & 5 & 6 \\
\hline Dizziness & 0 & 1 & 2 & 3 & 4 & 5 & 6 \\
\hline Blurred vision & 0 & 1 & 2 & 3 & 4 & 5 & 6 \\
\hline Balance problems & 0 & 1 & 2 & 3 & 4 & 5 & 6 \\
\hline Sensitivity to light & 0 & 1 & 2 & 3 & 4 & 5 & 6 \\
\hline Sensitivity to noise & 0 & 1 & 2 & 3 & 4 & 5 & 6 \\
\hline Feeling slowed down & 0 & 1 & 2 & 3 & 4 & 5 & 6 \\
\hline Feeling like "in a fog" & 0 & 1 & 2 & 3 & 4 & 5 & 6 \\
\hline "Don't feel right" & 0 & 1 & 2 & 3 & 4 & 5 & 6 \\
\hline Difficulty concentrating & 0 & 1 & 2 & 3 & 4 & 5 & 6 \\
\hline Difficulty remembering & 0 & 1 & 2 & 3 & 4 & 5 & 6 \\
\hline Fatigue or low energy & 0 & 1 & 2 & 3 & 4 & 5 & 6 \\
\hline Confusion & 0 & 1 & 2 & 3 & 4 & 5 & 6 \\
\hline Drowsiness & 0 & 1 & 2 & 3 & 4 & 5 & 6 \\
\hline Trouble falling asleep & 0 & 1 & 2 & 3 & 4 & 5 & 6 \\
\hline More emotional & 0 & 1 & 2 & 3 & 4 & 5 & 6 \\
\hline Irritability & 0 & 1 & 2 & 3 & 4 & 5 & 6 \\
\hline Sadness & 0 & 1 & 2 & 3 & 4 & 5 & 6 \\
\hline Nervous or Anxious & 0 & 1 & 2 & 3 & 4 & 5 & 6 \\
\hline
\end{tabular}

Nervous or Anxious

Total number of symptoms (Maximum possible 22)

Symptom severity score (Maximum possible 132

Do the symptoms get worse with physical activity?

Do the symptoms get worse with mental activity?

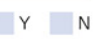

self rated
clinician interview

Overall rating: If you know the athlete well prior to the injury, how different is the athlete acting compared to his/her usual self?

Please circle one response:

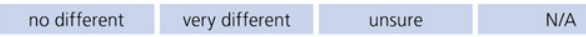

Scoring on the SCAT3 should not be used as a stand-alone method to diagnose concussion, measure recovery or make decisions about an athlete's readiness to return to competition after concussion. Since signs and symptoms may evolve over time, it is important to consider repeat evaluation in the acute assessment of concussion.

\section{COGNITIVE \& PHYSICAL EVALUATION}

\section{Cognitive assessment}

Standardized Assessment of Concussion (SAC) ${ }^{4}$

Orientation (1 point for each correct answer)

What month is it?

What is the date today?

What is the day of the week?

What year is it?

What time is it right now? (within 1 hour)

Orientation score

\begin{tabular}{|l|l|}
\hline 0 & 1 \\
\hline 0 & 1 \\
\hline 0 & 1 \\
\hline 0 & 1 \\
\hline 0 & 1 \\
\hline
\end{tabular}

Immediate memory

\begin{tabular}{l|l|l|l|l|l}
\hline List & Trial 1 & Trial 2 & Trial 3 & Alternative word list
\end{tabular}

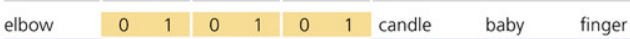

\begin{tabular}{l|ll|ll|ll|l|l|l} 
apple & 0 & 1 & 0 & 1 & 0 & 1 & paper & monkey penny
\end{tabular}

\begin{tabular}{l|ll|ll|ll|l|l|l|l}
\hline carpet & 0 & 1 & 0 & 1 & 0 & 1 & sugar & perfume blanket
\end{tabular}

\begin{tabular}{l|ll|ll|ll|l|l|l} 
saddle & 0 & 1 & 0 & 1 & 0 & 1 & sandwich sunset lemon
\end{tabular}

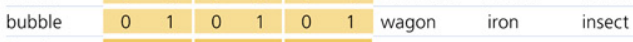

Total

Immediate memory score total

Concentration: Digits Backward

\begin{tabular}{l||l|l|l}
\hline List & Trial 1 Alternative digit list
\end{tabular}

\begin{tabular}{l|llllll}
$4-9-3$ & 0 & 1 & $6-2-9$ & $5-2-6$ & $4-1-5$
\end{tabular}

\begin{tabular}{l|lllll}
$3-8-1-4$ & 0 & 1 & $3-2-7-9$ & $1-7-9-5$ & $4-9-6-8$
\end{tabular}

\begin{tabular}{l|ll|lll}
$6-2-9-7-1$ & 0 & 1 & $1-5-2-8-6$ & $3-8-5-2-7$ & $6-1-8-4-3$
\end{tabular}

$\begin{array}{llllll}7-1-8-4-6-2 & 0 & 1 & 5-3-9-1-4-8 & 8-3-1-9-6-4 & 7-2-4-8-5-6\end{array}$

Total of 4

Concentration: Month in Reverse Order (1 pt. for entire sequence correct) \begin{tabular}{|l|l|l|}
\hline Dec-Nov-Oct-Sept-Aug-Jul-Jun-May-Apr-Mar-Feb-Jan & 0 & 1 \\
\hline
\end{tabular}

Concentration score

5 Neck Examination:

Range of motion Tenderness Upper and lower limb sensation \&strength Findings:

\section{Balance examination}

Do one or both of the following tests.

Footwear (shoes, barefoot, braces, tape, etc)

\section{Modified Balance Error Scoring System (BESS) testing ${ }^{5}$}

Which foot was tested (i.e. which is the non-dominant foot) Left Testing surface (hard floor, field, etc)

Condition

Double leg stance:

Single leg stance (non-dominant foot):

Tandem stance (non-dominant foot at back)

And/Or

Tandem gait ${ }^{6,7}$

Time (best of 4 trials): __ seconds

7 Coordination examination Upper limb coordination

Which arm was tested:

Coordination score

\section{SAC Delayed Recall ${ }^{4}$}

Delayed recall score 


\section{INSTRUCTIONS}

Words in Italics throughout the SCAT3 are the instructions given to the athlete by the tester.

\section{Symptom Scale}

"You should score yourself on the following symptoms, based on how you feel now"

To be completed by the athlete. In situations where the symptom scale is being completed after exercise, it should still be done in a resting state, at least 10 minutes post exercise.

Forsible is 22 .

For Symptom severity score, add all scores in table, maximum possible is $22 \times 6=132$.

\section{$\mathrm{SAC}^{4}$}

Immediate Memory

"I am going to test your memory. I will read you a list of words and when I am done, repeat back as many words as you can remember, in any order:

\section{Trials $2 \& 3$}

"I am going to repeat the same list again. Repeat back as many words as you can remember in any order, even if you said the word before."

Complete all 3 trials regardless of score on trial 1\&2. Read the words at a rate of one per second. Score 1 pt. for each correct response. Total score equals sum across all 3 trials. Do not inform the athlete that delayed recall will be tested.

\section{Concentration}

\section{Digits backward}

"I am going to read you a string of numbers and when I am done, you repeat them back to me backwards, in rev

If correct, go to next string length. If incorrect, read trial 2 . One point possible for each string If correct, go to next string length. If incorrect, read trial 2 . One point possible for each string
length. Stop after incorrect on both trials. The digits should be read at the rate of one per second.

\section{Months in reverse order}

Now tell me the months of the year in reverse order. Start with the last month and go backward. So you'll say December, November ... Go ahead"

$1 \mathrm{pt}$. for entire sequence correct

Delayed Recall

The delayed recall should be performed after completion of the Balance and Coordination Examination

"Do you remember that list of words / read a few times earlier? Tell me as many words from the list as you can remember in any order:"

Score $1 \mathrm{pt}$. for each correct response

\section{Balance Examination}

\section{Modified Balance Error Scoring System (BESS) testing ${ }^{5}$}

This balance testing is based on a modified version of the Balance Error Scoring System (BESS) $)^{5}$. A stopwatch or watch with a second hand is required for this testing. "I am now going to test your balance. Please take your shoes off, roll up your pant legs above ankle (if applicable), and remove any ankle taping (if applicable). This test will consist of three twenty second tests with different stances."

\section{(a) Double leg stance:}

The first stance is standing with your feet together with your hands on your hips and with your eyes closed. You should try to maintain stability in that position for 20 seconds. I will be counting the number of times you move out of this position. I will start timing when you are set and have closed your eyes.

\section{(b) Single leg stance:}

"If you were to kick a ball, which foot would you use? [This will be the dominant foot] Now stand on your non-dominant foot. The dominant leg should be held in approximately 30 degrees of hip flexion and 45 degrees of knee flexion. Again, you should try to maintain stability for 20 seconds with your hands on your hips and your eyes closed. I will be counting the number af times you move out of this position alf you stumble out of this position, open your

\section{(c) Tandem stance:}

"Now stand heel-to-toe with your non-dominant foot in back. Your weight should be evenly distributed across both feet. Again, you should try to maintain stability for 20 seconds with your hands on your hips and your eyes closed. I will be counting the number of times you move out of this position. If you stumble out of this position, open your eyes and return to the start position and continue balancing. I will start timing when you are set and have closed your eyes."

\author{
Balance testing - types of errors \\ 1. Hands lifted off iliac crest \\ 2. Opening eyes \\ 4. Moving hip into $>30$ degrees abduction \\ 5. Lifting forefoot or heel \\ 6. Remaining out of test position $>5 \mathrm{sec}$
}

Each of the 20-second trials is scored by counting the errors, or deviations from the proper stance, accumulated by the athlete. The examiner will begin counting errors only after the individual has assumed the proper start position. The modified BESS is calculated by adding one error point for each error during the three BESS is calculated by adding one error point for each error during the three
20 -second tests. The maximum total number of errors for any single con20 -second tests. The maximum total number of errors for any single con-
dition is 10 . If a athlete commits multiple errors simultaneously, only one error is recorded but the athlete should quickly return to the testing position, and counting should resume once subject is set. Subjects that are unable to maintain the testing procedure for a minimum of five seconds at the start are assigned the highest possible score, ten, for that testing condition.

OPTION: For further assessment, the same 3 stances can be performed on a surface of medium density foam (e.g., approximately $50 \mathrm{~cm} \times 40 \mathrm{~cm} \times 6 \mathrm{~cm}$ ).

\section{Tandem Gait ${ }^{6,7}$}

Participants are instructed to stand with their feet together behind a starting line (the test is best done with footwear removed). Then, they walk in a forward direction as quickly and as accurately as possible along a $38 \mathrm{~mm}$ wide (sports tape), 3 meter line with an alternate foot heel-to-toe gait ensuring that they approximate their heel and toe on each step. Once they
cross the end of the $3 m$ line they turn 180 degrees and return to the starting point using the cross the end of the $3 \mathrm{~m}$ line, they turn 180 degrees and return to the starting point using the
same gait. A total of 4 trials are done and the best time is retained. Athletes should complete same gait. A total of 4 trials are done and the best time is retained. Athletes should complete
the test in 14 seconds. Athletes fail the test if they step off the line, have a separation between their heel and toe, or if they touch or grab the examiner or an object. In this case, the time is not recorded and the trial repeated, if appropriate.

\section{Coordination Examination}

\section{Upper limb coordination}

Finger-to-nose (FTN) task:

"I am going to test your coordination now. Please sit comfortably on the chair with your eyes open and your arm (either right or left) outstretched (shoulder flexed to 90 degrees and elbow and fingers extended), pointing in front of you. When I give a start signal, I would like you to perform five successive finger to nose repetitions using your index finger to touch the tip of the nose, and then return to the starting position, as quickly and as accurately as possible."

Scoring: 5 correct repetitions in $<4$ seconds $=1$

Note for testers: Athletes fail the test if they do not touch their nose, do not fully extend their elbow or do not perform five repetitions. Failure should be scored as 0 .

\section{References \& Footnotes}

1. This tool has been developed by a group of international experts at the 4 th International Consensus meeting on Concussion in Sport held in Zurich. Switzerland in November 2012. The full details of the conference outcomes and the authors of the tool are published in The BJSM Injury Prevention and Health Protection, 2013, Volume 47 , Issue 5 . The outcome paper will also be simultaneously co-published in other leading biomedical journals with the copyright held by the Concussion in Sport Group, to allow unrestricted distribution, providing no alterations are made.

2. McCrory P et al., Consensus Statement on Concussion in Sport - the 3rd International Conference on Concussion in Sport held in Zurich, November 2008. British Journal of Sports Medicine 2009; 43: i76-89.

3. Maddocks, DL; Dicker, GD; Saling, MM. The assessment of orientation following concussion in athletes. Clinical Journal of Sport Medicine. 1995; 5(1): 32-3.

4. McCrea M. Standardized mental status testing of acute concussion. Clinical Journal of Sport Medicine. 2001; 11: 176-181.

5. Guskiewicz KM. Assessment of postural stability following sport-related concussion. Current Sports Medicine Reports. 2003; 2: 24-30

6. Schneiders, A.G., Sullivan, S.J., Gray, A., Hammond-Tooke, G. \&McCrory, P. Normative values for 16-37 year old subjects for three clinical measures of motor performance used in the assessment of sports concussions. Journal of Science and Medicine in Sport. 2010; 13(2): 196-201.

7. Schneiders, A.G., Sullivan, S.J., Kvarnstrom. J.K., Olsson, M., Yden. T.\& Marshall, S.W. The effect of footwear and sports-surface on dynamic neurological screening in sport-related concussion. Journal of Science and Medicine in Sport. 2010; 13(4): $382-386$ 


\section{ATHLETE INFORMATION}

Any athlete suspected of having a concussion should be removed from play, and then seek medical evaluation.

\section{Signs to watch for}

Problems could arise over the first $24-48$ hours. The athlete should not be left alone and must go to a hospital at once if they:

- Have a headache that gets worse

- Are very drowsy or can't be awakened

- Can't recognize people or places

- Have repeated vomiting

- Behave unusually or seem confused; are very irritable

- Have seizures (arms and legs jerk uncontrollably)

- Have weak or numb arms or legs

- Are unsteady on their feet; have slurred speech

Remember, it is better to be safe.

Consult your doctor after a suspected concussion.

\section{Return to play}

Athletes should not be returned to play the same day of injury.

When returning athletes to play, they should be medically cleared and then follow a stepwise supervised program, with stages of progression.

For example:

\begin{tabular}{|c|c|c|}
\hline Rehabilitation stage & $\begin{array}{l}\text { Functional exercise at each stage } \\
\text { of rehabilitation }\end{array}$ & Objective of each stage \\
\hline No activity & Physical and cognitive rest & Recovery \\
\hline Light aerobic exercise & $\begin{array}{l}\text { Walking, swimming or stationary cycling } \\
\text { keeping intensity. } 70 \% \text { maximum predicted } \\
\text { heart rate. No resistance training }\end{array}$ & Increase heart rate \\
\hline Sport-specific exercise & $\begin{array}{l}\text { Skating drills in ice hockey, running drills in } \\
\text { soccer. No head impact activities }\end{array}$ & Add movement \\
\hline $\begin{array}{l}\text { Non-contact } \\
\text { training drills }\end{array}$ & $\begin{array}{l}\text { Progression to more complex training drills, } \\
\text { eg passing drills in football and ice hockey. } \\
\text { May start progressive resistance training }\end{array}$ & $\begin{array}{l}\text { Exercise, coordination, and } \\
\text { cognitive load }\end{array}$ \\
\hline Full contact practice & $\begin{array}{l}\text { Following medical clearance participate in } \\
\text { normal training activities }\end{array}$ & $\begin{array}{l}\text { Restore confidence and assess } \\
\text { functional skills by coaching staff }\end{array}$ \\
\hline Return to play & Nort & \\
\hline
\end{tabular}

There should be at least 24 hours (or longer) for each stage and if symptoms recur the athlete should rest until they resolve once again and then resume the program at the previous asymptomatic stage. Resistance training should only be added in the later stages.

If the athlete is symptomatic for more than 10 days, then consultation by a medical practitioner who is expert in the management of concussion, is recommended.

Medical clearance should be given before return to play.

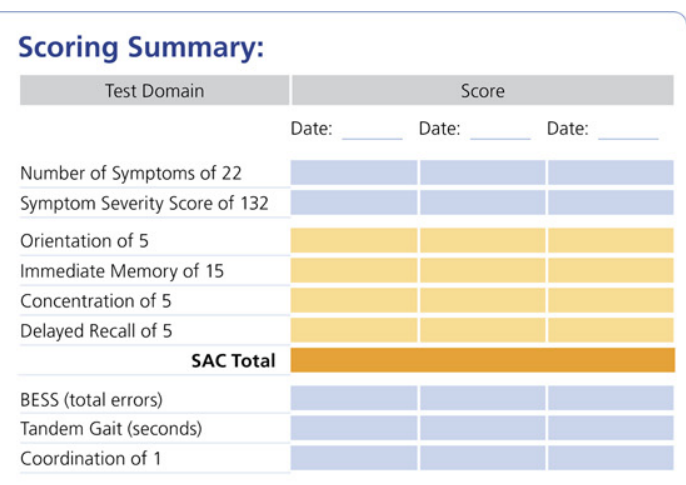

Notes:

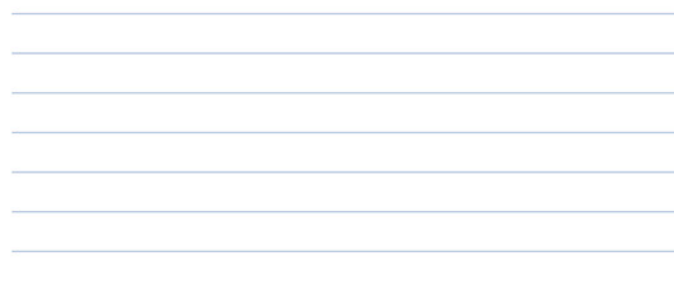

\section{CONCUSSION INJURY ADVICE}

\section{(To be given to the person monitoring the concussed athlete)}

This patient has received an injury to the head. A careful medical examination has been carried out and no sign of any serious complications has been found. Recovery time is variable across individuals and the patient will need monitoring for a further period by a responsible adult. Your treating physician will provide guidance as to this timeframe.

If you notice any change in behaviour, vomiting, dizziness, worsening headache, double vision or excessive drowsiness, please contact your doctor or the nearest hospital emergency department immediately.

\section{Other important points:}

- Rest (physically and mentally), including training or playing sports

until symptoms resolve and you are medically cleared

- No alcohol

- No prescription or non-prescription drugs without medical supervision.

Specifically:

No sleeping tablets

Do not use aspirin, anti-inflammatory medication or sedating pain killers

- Do not drive until medically cleared

- Do not train or play sport until medically cleared

Clinic phone number

\section{Patient's name}

Date/time of injury

Date/time of medical review

Treatingphysician 